\title{
Identification and expression analysis of OsLPR family revealed the potential roles of $O s L P R 3$ and 5 in maintaining phosphate homeostasis in rice
}

Yue Cao ${ }^{1}$, Hao Ai ${ }^{1}$, Ajay Jain ${ }^{2}$, Xueneng Wu' ${ }^{1}$ Liang Zhang ${ }^{1}$, Wenxia Pei ${ }^{1}$, Aiqun Chen ${ }^{1}$, Guohua X ${ }^{1}$ and Shubin Sun ${ }^{1,3^{*}}$

\begin{abstract}
Background: Phosphorus (P), an essential macronutrient, is often limiting in soils and affects plant growth and development. In Arabidopsis thaliana, Low Phosphate Root1 (LPR1) and its close paralog LPR2 encode multicopper oxidases (MCOs). They regulate meristem responses of root system to phosphate (Pi) deficiency. However, the roles of $L P R$ gene family in rice (Oryza sativa) in maintaining Pi homeostasis have not been elucidated as yet.

Results: Here, the identification and expression analysis for the homologs of $L P R 1 / 2$ in rice were carried out. Five homologs, hereafter referred to as OSLPR1-5, were identified in rice, which are distributed on chromosome1 over a range of $65 \mathrm{~kb}$. Phylogenetic analysis grouped OsLPR1/3/4/5 and OsLPR2 into two distinct sub-clades with OsLPR3 and 5 showing close proximity. Quantitative real-time RT-PCR (qRT-PCR) analysis revealed higher expression levels of OsLPR3-5 and OSLPR2 in root and shoot, respectively. Deficiencies of different nutrients ie, $\mathrm{P}$, nitrogen $(\mathrm{N})$, potassium $(\mathrm{K})$, magnesium $(\mathrm{Mg})$ and iron (Fe) exerted differential and partially overlapping effects on the relative expression levels of the members of OsLPR family. Pi deficiency (-P) triggered significant increases in the relative expression levels of OSLPR3 and 5. Strong induction in the relative expression levels of OsLPR3 and 5 in osphr2 suggested their negative transcriptional regulation by OsPHR2. Further, the expression levels of OsLPR3 and 5 were either attenuated in ossizl and ospho2 or augmented in rice overexpressing OsSPX1.
\end{abstract}

Conclusions: The results from this study provided insights into the evolutionary expansion and a likely functional divergence of OSLPR family with potential roles of OsLPR3 and 5 in the maintenance of Pi homeostasis in rice.

Keywords: Rice, Phosphate deficiency, OsLPR family, OsLPR3, OsLPR5, Phosphate homeostasis

\footnotetext{
* Correspondence: sunshubin@njau.edu.cn

${ }^{1}$ State Key Laboratory of Crop Genetics and Germplasm Enhancement, Key Laboratory of Plant Nutrition and Fertilization in Low-Middle Reaches of the Yangtze River, Ministry of Agriculture, Nanjing Agricultural University, Nanjing 210095, China

${ }^{3}$ State Key Laboratory of Crop Genetics and Germplasm Enhancement, Key Laboratory of Plant Nutrition and Fertilization in Low-Middle Reaches of the Yangtze River, Ministry of Agriculture, College of Resources and

Environmental Science, Nanjing Agricultural University, Nanjing 210095,

China

Full list of author information is available at the end of the article
} 


\section{Background}

Phosphorus (P), one of the essential macronutrients, is required for several biochemical and physiological processes and is a component of key macromolecules including nucleic acids, ATP and membrane phospholipids [1]. P is absorbed from rhizosphere as phosphate (Pi), which is often not easily available to plants due to its slow diffusion rates in soils and/or fixation as immobile organic Pi [2]. Limited Pi availability adversely affects growth and development of plants [3].

In Arabidopsis thaliana, Pi deficiency triggers progressive loss of meristematic activity in primary root tip thereby inhibiting primary root growth (PRG) [4]. LPR1 (At1g23010) and its close paralog LPR2 (At1g71040), encoding multicopper oxidases (MCOs), are major quantitative trait loci (QTLs) associated with $\mathrm{Pi}$ deficiencymediated inhibition of PRG $[5,6]$. Loss-of-function mutations in LPR1 and LPR2 affect Pi deficiency-mediated inhibition of PRG [6]. However, unlike Arabidopsis, Pi deficiency either does not exert any significant effect on PRG of taxonomically diverse dicots and monocots $[7,8]$ or triggeres augmented PRG in rice $[9,10]$. These studies suggested that Pi deficiency-mediated inhibition of PRG is not a global response across different plant species. This raised an obvious question about the likely role of homologs of $L P R 1 / 2$ particularly in species such as rice in which Pi deficiency has a rather contrasting influence on PRG.

Nuclear-localized SIZ1 (At5g60410) encodes a small ubiquitin-like modifier (SUMO) E3 ligase1 and sumoylates transcription factor (TF) PHR1 (At4g28610) in Arabidopsis [11]. PHR1 plays a pivotal role in regulating the expression of Pi 3starvation-responsive (PSR) genes whose promoters are enriched with PHR1-binding sequence (P1BS) motif [12]. PHR1 is a pivotal upstream component of the $\mathrm{Pi}$ sensing and signaling cascade comprising miR399s, IPS1 (At3g09922), PHO2 (At2g33770), SPX1 (At5g20150), Pi transporters Pht1;8 (At1g20860),Pht1;9 (At1g76430) and a subset of other PSR genes [13-15]. Interestingly though, promoters of both LPR1 and LPR2 do not have P1BS motif, which suggests a lack of any regulatory influence of PHR1 on the expression of these genes. Therefore, the identification of TFs that regulate $L P R 1 / 2$ solicits further studies.

Rice, one of the most important cereal crops, feeds over one-third population of the world and sometimes is the only source of calories [16, 17]. Rice is often cultivated in rain-fed system on soils that are poor in $\mathrm{Pi}$ availability, which affects its growth and development and consequently the yield potential [16]. Therefore, it is increasingly becoming imperative to decipher the intricacies involved in the maintenance of $\mathrm{Pi}$ homeostasis for developing rice with higher Pi use efficiency for the sustainability of agriculture. Pi starvation signal transduction pathway is highly conserved between Arabidopsis and rice [17]. In this context, several homologs of Arabidopsis in rice ie, OsPHR2 [18, 19], OsPHO2 [20, 21], OsSPX1 and OsSPX2 [22] have been functionally characterized and are pivotal components of $\mathrm{Pi}$ sensing and signaling cascade [17]. However, the roles of homologs of $L P R 1 / 2$ in rice during the maintenance of $\mathrm{Pi}$ homeostasis have not been elucidated as yet.

In this study, the identification and expression analysis of OsLPR1-5 in rice were carried out. Phylogenetic analysis revealed their grouping into two distinct subclades. Differential expression of these genes under both Pi-replete and Pi-deprived conditions and also under other nutrient deficiencies suggested functional divergence across them. Further, analyses of the relative expression levels of OsLPR3 and OsLPR5 in loss-of-function mutants (ossiz1, osphr2 and ospho2) and transgenic rice overexpressing either OsPHR2 or OsSPX1 provided an insight into their potential roles in Pi sensing and signaling cascade.

\section{Results and discussion}

Comparative structure analysis of LPRs in Arabidopsis and rice

Protein sequences of Arabidopsis LPR1-2 were used as queries by TBLASTN search in National Center for Biotechnology Information (NCBI) database, which identified five homologous genes in the rice genome and hereafter referred to as OSLPR1-5. Details of their locus ID, cDNA accession number and protein characteristics are listed in Additional file 1. OsLPR1-5 are localized closely within a range of $65 \mathrm{~kb}$ on the short arm of chromosome 1 (Additional file 2). DNAMAN 7.0 program was used for multi-sequence alignments of nucleotides and amino acids of LPR1-2 and OSLPR1-5 and per cent identity matrices across them were determined (Fig. 1a). Nucleotide equence identity (SI) was $85 \%$ between OsLPR3 and OsLPR4 and $67.2 \%$ between OsLPR2 and OsLPR3. Amino acid SI was $68.3 \%$ between OsLPR3 and OsLPR5 and $40.9 \%$ between OsLPR2 and OsLPR5. The analysis suggested a relative closeness of OsLPR5 to OsLPR3 and distant from OsLPR2. Nucleotide SI of LPR1 with OsLPR1 and OsLPR4 were 58 and $54.1 \%$, respectively. Amino acid SI varied from $57 \%$ between OsLPR1 and LPR1 to $44.8 \%$ between OsLPR5 and LPR2. This suggested that members of the OsLPR family are phylogenetically more closely related to each other than to LPRs. For comparative analysis of the number and position of exons and introns in LPRs from rice and Arabidopsis, their full-length cDNA sequences were aligned with their corresponding genomic DNA sequences (Fig. 1b). Number of exons ranged from four (LPR1-2), three (OsLPR1/2/5) to two (OsLPR3/4). In rice, the longest exon varied from 1446 bp in OsLPR5 to 1551 bp in OsLPR3, while it was 1125 bp in both LPR1-2. With a notable exception of OsLPR4, the last exon of LPRs and OsLPRs was $54 \mathrm{bp}$ in length. Introns also exhibited variation in their number ranging from three (LPR1-2 and OsLPR5), two 


\begin{tabular}{|c|c|c|c|c|c|c|c|}
\hline & \multicolumn{7}{|c|}{ Amino acids Identity (\%) } \\
\hline & OsLPR1 & OsLPR2 & OsLPR3 & OsLPR4 & OsLPR5 & AtLPR1 & AtLPR2 \\
\hline OsLPR1 & & 52.8 & 60.2 & 63.1 & 56.2 & 57.0 & 55.3 \\
\hline OSLPR2 & 67.7 & & 47.9 & 46.2 & 40.9 & 53.3 & 52.5 \\
\hline OsLPR3 & 73.9 & 67.2 & & 65.4 & 68.3 & 51.8 & 50.2 \\
\hline OsLPR4 & 71.0 & 65.9 & 85.0 & & 64.8 & 51.4 & 50.9 \\
\hline OSLPR5 & 74.3 & 66.6 & 79.6 & 77.7 & & 46.1 & 44.8 \\
\hline AtLPR1 & 58.0 & 56.0 & 55.8 & 54.1 & 55.4 & & 78.7 \\
\hline AtLPR2 & 56.3 & 55.8 & 55.7 & 55.2 & 54.7 & 76.7 & \\
\hline
\end{tabular}

b

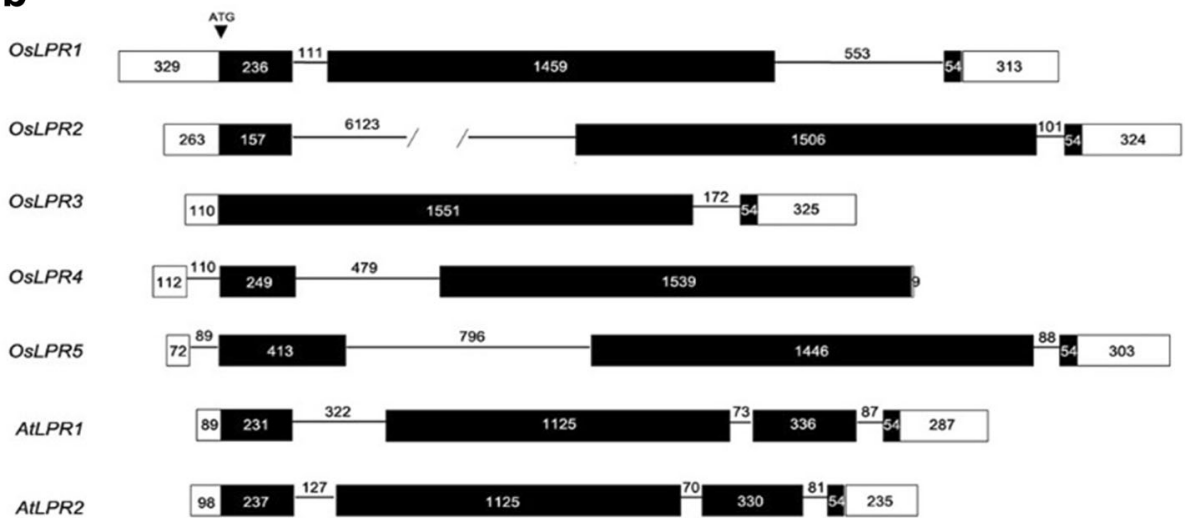

Fig. 1 Comparative identity matrices and gene structures of $L P R$ genes in Arabidopsis and rice. a DNAMAN 7.0 program was used for multi-sequence alignments of nucleotides and amino acids for determining per cent identity matrices across them. $\mathbf{b}$ Schematic representation of genes showing UTR (empty boxes), CDS (black boxes) and introns (black lines) with numbers indicating length of each of them

(OsLPR1/2/4) to one (OsLPR3) with length varying from $70 \mathrm{bp}$ in LPR2 to $6123 \mathrm{bp}$ in OsLPR2. Further, the $5^{\prime}$ untranslated regions (UTR) of OsLPR4/5 were disrupted by an intron. The analysis thus revealed both the divergence and conservation of $L P R$ genes in Arabidopsis and rice.

\section{Phylogenetic analysis of $L P R$ genes}

LPR1 and LPR2 were used as queries in the BLASTP search on NCBI and PLAZA databases, which identified 53 LPR homologs from taxonomically diverse higher (15 dicots, 8 monocots and 2 gymnosperms) and lower plants ( 1 bryophyte and 3 algae). An unrooted phylogenetic tree of all the homologs identified was reconstructed using MEGA 4.0 using the neighbor-joining method (Fig. 2). Monocot LPR proteins grouped into clades $a, b$ and $c$ represented by yellow, red and purple lines, respectively, on the phylogenetic tree. Except OsLPR2, OsLPR1 and OsLPR3-5 clubbed together in clade $b$ with a closer evolutionary distance along with LPRs from Sorghum bicolor (SB03G007440, SB03G007480), Setaria italic (XP004968084.1) and Zea mays (ZM03G06390). Grouping of OsLPR3 and OsLPR5 in a distinct single subbranch was consistent with their high nucleotide and amino acid SI (Fig. 1a). In a single subclade, OsLPR3 and OsLPR5 were inparalogs but outparalogs of OsLPR1/2/4. OsLPR2 was placed in clade $a$ along with LPRs from the members of the grass family ie, S. bicolor (SB03G007470), Z. mays (ZM03G06360), Aegilop stauschii (EMT22339.1), Triticum urartu (EMS54345.1), Hordeum vulgare (BAJ85891.1) and Brachypodium distachyon (BD2G01850). Orthologs of OsLPR $1 / 2 / 4$ were also found in other monocot species. The clade $c$ comprising LPRs from $B$. distachyon (BD4G 11770, BD3G22317), Z. mays (ZM03G8070) and S. bicolor (SB03G009410) revealed long evolutionary distance from both clades $a$ and $b$. Although all the LPRs from dicots formed a distinct clade (green), notable exception was the placement of LPR from Manihot esculenta (ME01284 G00050) (grey clade) between clades $a$ and $b$. Both AtLPR1 and AtLPR2 exhibited close phylogenetic relationships with LPRs from Capsella rubella (EOA34953.1 and EOA 39992.1). LPRs from gymnosperm (Selaginella moellendorffii), bryophyte (Physcomitrella patens) and algae (Micromonas pusilla, Volvox carteri and Chlamydomonas reinhardtii) grouped in grey clade. It is apparent from this phylogenetic analysis that LPRs in monocotyledonous species are closely related suggesting a likely duplication event preceding the split between monocots and dicots. On the contrary, LPR paralogs in dicotyledonous species were closely related indicating duplication following the split between monocots and dicots. Therefore, it could be assumed that OsLPRs may have functions similar to orthologs from other monocotyledonous species but different from LPRs in dicotyledonous species including Arabidopsis. Overall, the analysis revealed the conservation of LPRs across taxonomically diverse higher and lower plant species. 


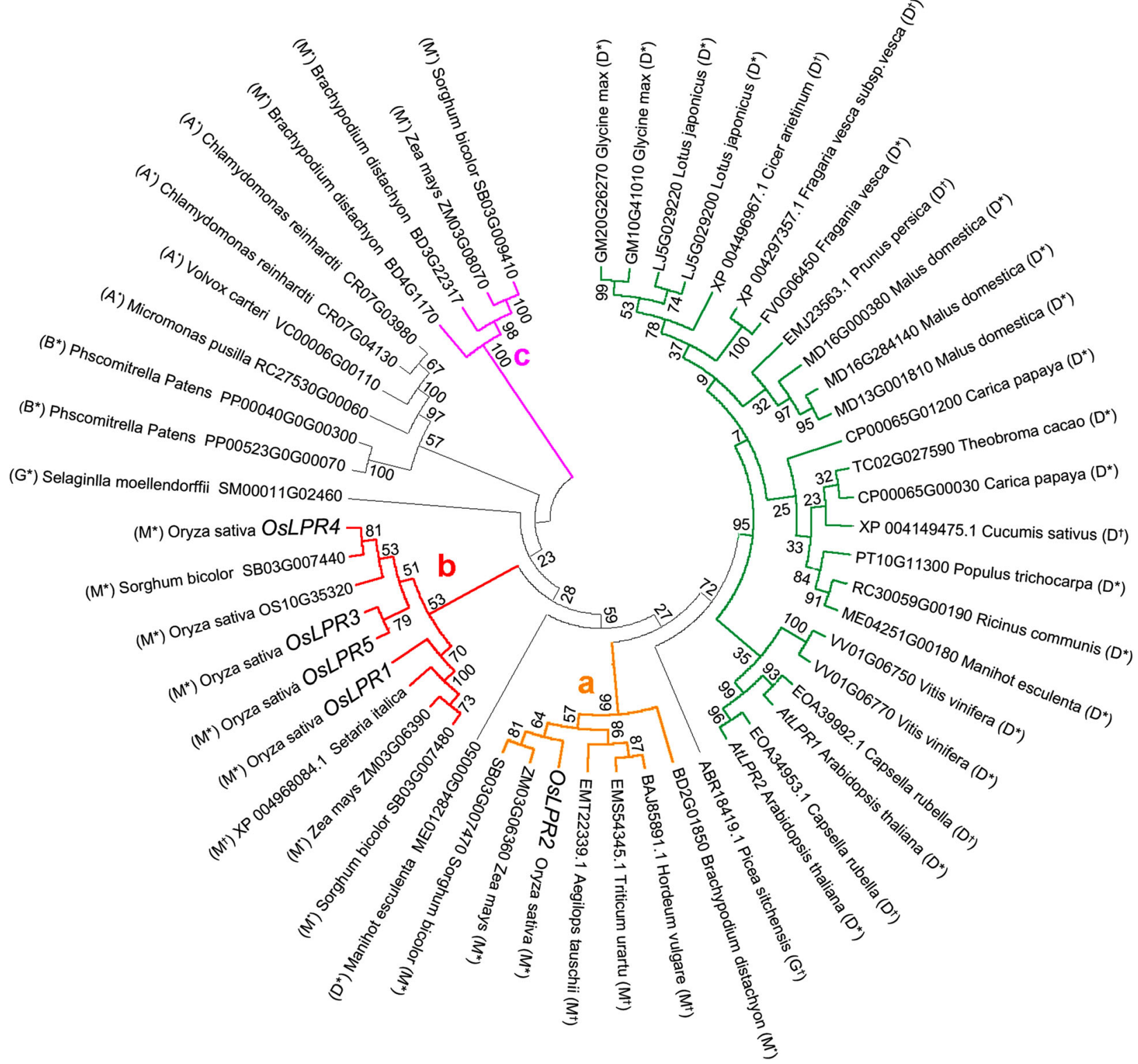

Fig. 2 Phylogenetic analysis of $L P R$ gene family in plants. Joint unrooted phylogenetic tree of 53 putative $L P R$ genes from 29 different higher and lower plant species representing dicots $(D)$, monocots $(M)$, gymnosperms $(G)$, bryophytes $(B)$ and algae $(A) .{ }^{*}$ and + represent species that have been sequenced and not sequenced as yet, respectively

\section{Cu-oxidase domain analysis of LPR proteins in rice}

Multicopper oxidase (MCO) facilitates oxidation of organic or metal ions, and trinuclear $\mathrm{Cu}$ cluster (TNC) is involved in the reduction of $\mathrm{O}_{2}$ [23]. In Arabidopsis, MCO activity of LPR proteins is pivotal for eliciting inhibition of primary root growth during Pi deficiency [6]. Pfam and NCBI protein databases (http://pfam.xfam.org/ and http:// www.ncbi.nlm.nih.gov/guide/proteins/\#databases) were employed for the analysis of the domain structures of $\mathrm{Cu}$ oxidase 1-3 and peroxidase in LPR proteins of higher and lower plant species that have been sequenced (Additional file 3). The analysis revealed significant differences in sizes and positions of $\mathrm{Cu}$-oxidase $1-3$ and peroxidase domains of putative LPR proteins of B. distachyon (BD4G11770, BD3G22317), Z. mays (ZM03G8070) and S. bicolor (SB03G009410) compared with other LPR proteins. Further, $\mathrm{Cu}$-oxidase domains were analyzed in OsLPR proteins (Fig. 3a). Cu-oxidase domains I, II and III were detected in OsLPR1, 3, 4 and 5 with a notable absence of $\mathrm{Cu}$-oxidase I domain in OsLPR2. Full-length deduced polypeptides of LPR proteins comprised 535638 amino acids. Clustal $\mathrm{X}$ and DNAMAN 7.0 programs were used for multiple-sequence alignment of amino acids of $\mathrm{Cu}$-oxidase I, II and III domains of 


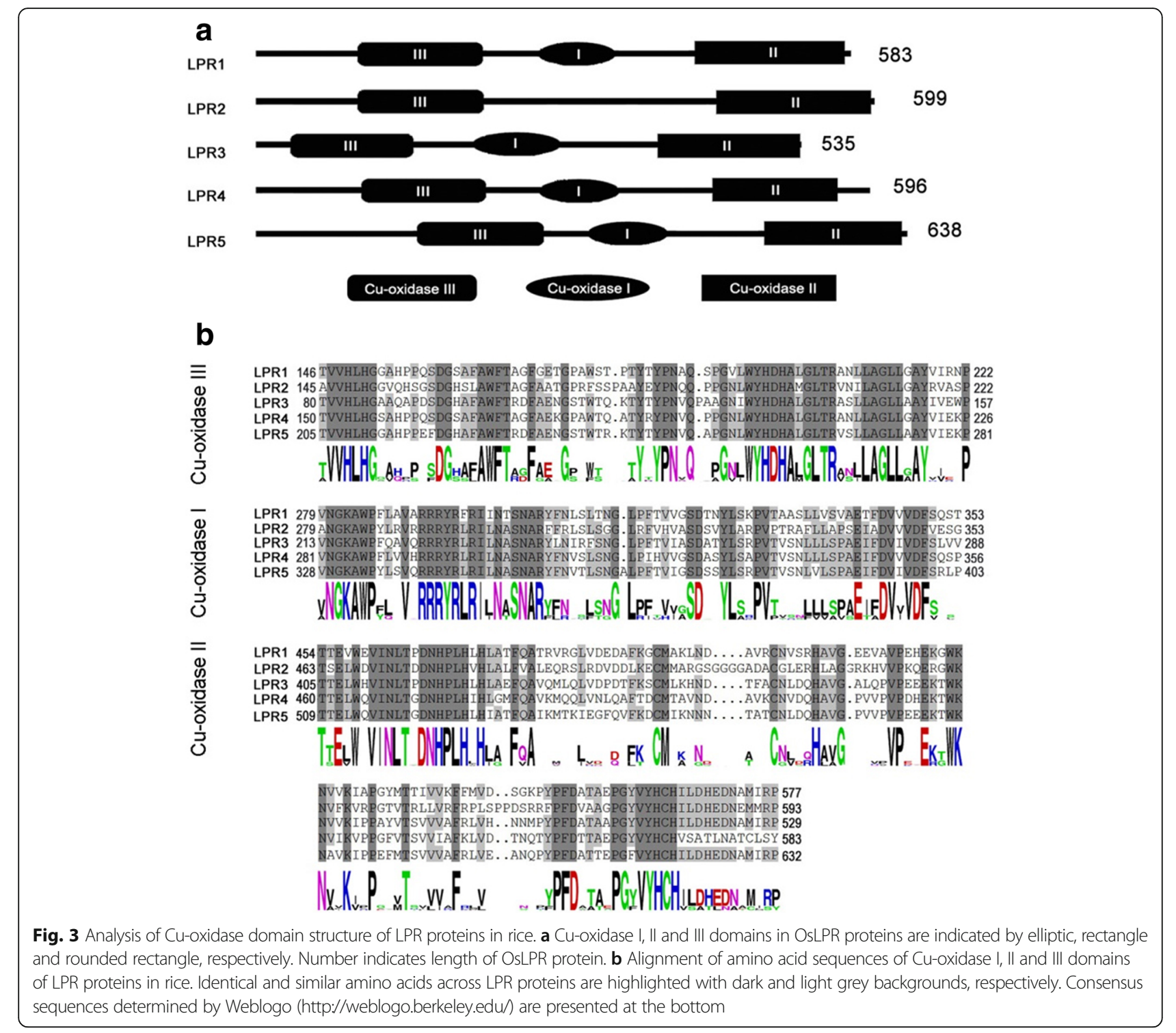

OsLPR proteins (Fig. 3b). The number of amino acids in Cu-oxidase I, II and III across OsLPRs were 74-75, 77-78 and 123-130, respectively. The analysis revealed significant conservation across all three domains of $\mathrm{Cu}$-oxidase in OsLPRs, which is critical for the maintenance of their optimal efficacy. Michigan State University (MSU) rice database (rice.plantbiology.msu.edu/index.shtml) search resulted in the identification of another 42 genes (27 laccases, 4 L-ascorbate oxidases and 10 monocopper oxidases), which are represented by three $\mathrm{Cu}$-oxidase domains. MEGA 4.0 was used for reconstructing an un-rooted dendrogram revealing phylogenetic relationship across these genes (Additional file 4). The analysis revealed a relative closeness of OsLPRs to the members of mono-copper oxidase subfamily. On the contrary, Nterminal regions of OsLPR proteins in Arabidopsis and rice showed a rather low per cent identity (Additional file 5).

\section{Tissue-specific expression profiles of OsLPRs}

To determine the spatiotemporal expression pattern of OsLPRs, qRT-PCR was performed at seedling (14-d-old) and flowering (60-d-old) stages (Fig. 4). At seedling stage, different tissues (1st, 2nd and 4th leaf blade, 2nd and 4th leaf sheath, basal stem and root zone I and II) were examined. Although expression of OsLPR1 was detected in all the tissues of the seedlings examined, its level was significantly higher in root zone II compared with other tissues. On the contrary, expression levels of OsLPR3 and OsLPR5 were largely detected in root zones and basal stem with relatively low or barely detectable expression levels in leaf blades and leaf sheaths. 


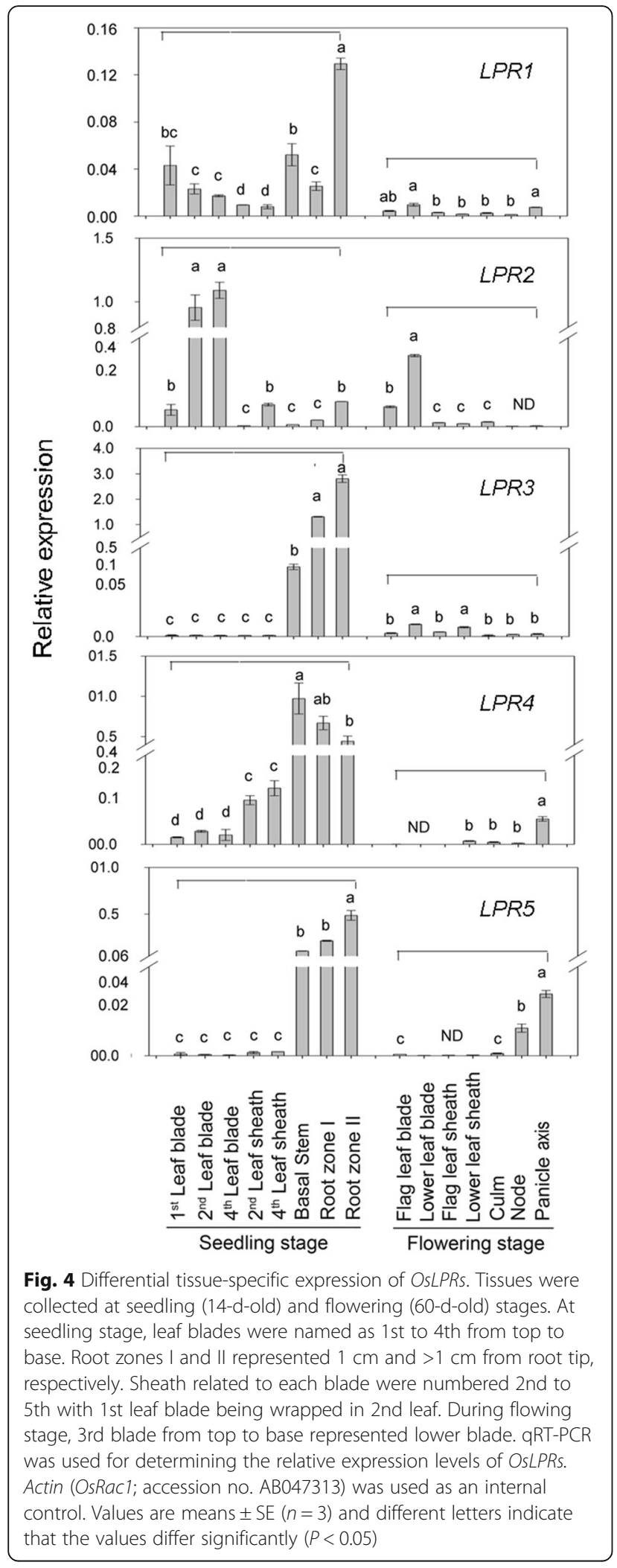

Expression of OsLPR4 was also relatively higher in basal stem and root zones compared with leaf sheath and leaf blade. High expression levels of OsLPR1/3/4/5 in roots suggested their potential roles in acquisition of nutrients by roots from the rhizosphere. The expression of OsLPR2 was significantly higher in 2nd and 4th leaf blades, moderate in 1st leaf blade, 4th leaf sheath and root zone II, and low in 2nd leaf sheath, basal stem and root zone I. This suggested a likely role of OsLPR2 in mobilization of nutrients to shoot. At flowering stage, the expression pattern of OsLPRs was examined in flag leaf blade, lower leaf blade, flag leaf sheath, lower leaf sheath, culm, node and panicle axis. Although low expression of OsLPR1 was detected in lower leaf blade and panicle axis, it could barely be observed in other tissues. OsLPR2 showed high transcript levels in flag and lower leaf blade, low transcript levels in leaf sheath (flag and lower) and culm and was not detected in node and panicle axis. The expression of OsLPR3 was relatively higher in lower leaf blade and lower leaf sheath compared with other tissues, while that of OsLPR4 was significantly higher in panicle axis compared with lower leaf sheath, culm and node and remained undetected in flag leaf blade, lower leaf blade and flag leaf sheath. In the case of OsLPR5, the expression pattern revealed a trend similar to OsLPR4 with a significantly higher level in panicle axis compared with other tissues. Pht1;1 (OsPT1), one of the 13 Pht1 Pi transporters in rice, expressed abundantly and constitutively in various cell types of both roots and shoots (Sun et al., 2012). Therefore, OsPT1 was used as a positive control for determining the relative expression levels of all the members of OSLPR family in different tissues of 21-d-old rice seedling (Additional file 6). Overall, the relative expression levels of different members of OsLPR family were higher at the seedling stage compared with flowering stage. The results suggested potentially different roles of the members of OsLPRs in a tissue- and development-specific manner. Functional divergence is also prevalent across the members of OsPTs (Pi transporters) and OsSPXs (SPX domain-containing proteins) gene families in rice [17].

\section{Nutrient deficiencies affect the expression profiles of OsLPRs}

Rice seedlings (14-d-old) were grown for $7 \mathrm{~d}$ in complete nutrient solution $(C)$ and in nutrient solution deprived of one of the nutrients ie, $\mathrm{Pi}$, nitrogen $(\mathrm{N})$, potassium $(\mathrm{K})$, magnesium $(\mathrm{Mg})$ and iron $(\mathrm{Fe})$. Roots of these seedlings were assayed for the relative expression levels of OsLPRs by qRT-PCR (Fig. 5). Compared with C, relative expression levels of OSLPR1 were significantly induced under $-\mathrm{K}$ and $-\mathrm{Fe}$ conditions, attenuated under $\mathrm{P}$ condition and remained unaffected under $-\mathrm{N}$ and $\mathrm{Mg}$ conditions. Although $-\mathrm{K}$ triggered a significant 


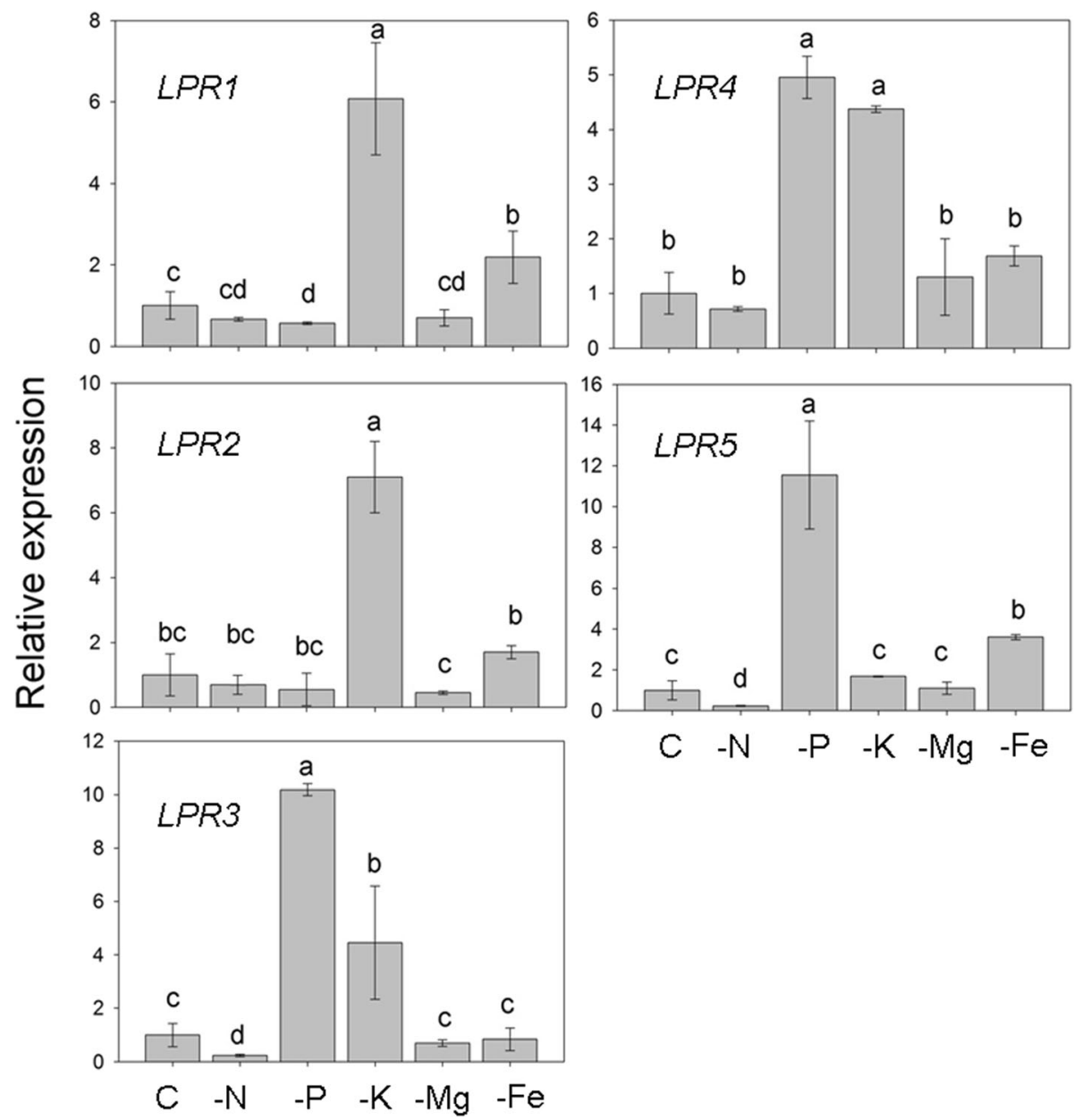

Fig. 5 Different nutrient deficiencies exert variable effects on the expression of OsLPRs in roots. Rice seedlings (14-d-old) were grown in complete nutrient solution $(C)$ and in nutrient solution deprived of one of the nutrients ie, Pi, N, K, Mg or Fe for $7 \mathrm{~d}$. qRT-PCR was used for determinin $\mathrm{g}$ the relative expression levels of OSLPRs in roots. Actin was used as an internal control. Values are means $\pm \operatorname{SE}(n=3)$ and different letters indicate that the values differ significantly $(P<0.05)$

increase in the relative expression level of $O s L P R 2$, other nutrient deficiencies did not exert any significant influence on its expression level compared with C. Relative expression levels of OsLPR3 were significantly induced under $-\mathrm{P}$ and $-\mathrm{K}$ conditions, reduced under $-\mathrm{N}$ condition and was unaffected under $-\mathrm{Mg}$ and - Fe conditions compared with C. Relative expression levels of OsLPR4 were elevated under $-\mathrm{P}$ and $-\mathrm{K}$ conditions but other nutrient deficiencies did not exert any significant influence on its expression level compared with C. Relative expression levels of OsLPR5 increased under $-\mathrm{P}$ and $-\mathrm{Fe}$ conditions, decreased under $-\mathrm{N}$ condition and remained comparable with $\mathrm{C}$ under $-\mathrm{K}$ and $-\mathrm{Mg}$ conditions. The analysis revealed variable effects of different nutrient deficiencies on the expression levels of OsLPRs. Among different nutrient deficiencies, $\mathrm{Pi}$ deficiency revealed wide spectrum effects ranging from induction (OsLPR3-5), attenuation (OsLPR1) and no influence (OsLPR2) on the relative expression level of these genes. This suggested their potentially variable and specific roles in regulating $\mathrm{Pi}$ homeostasis in rice. In Arabidopsis, LPR1 has been shown to play a pivotal role in inhibition of primary root growth in response to sensing local Pi deprivation [6, 24]. However, unlike taproot system in Arabidopsis, rice has a fibrous root system [25] and deficiency of Pi triggers its elongation $[9,10,26]$. This raised a pertinent question about a likely role, if any, of any of the Pi-responsive members of OsLPRs in Pi deficiency-mediated developmental responses of rice root system. Analysis of their loss-of-function mutants could provide a better insight, which requires further comprehensive studies. Variable responses to Pi deficiency have also been reported for members of gene family with SPX (SYG1/PHO81/XPR1) domain, which are designated as OsSPX1-6. Among these, OsSPX 1,2,3,5 and 6 are responsive to Pi starvation [27]. Although OsSPX4 is not responsive to Pi deficiency, SPX4 
interacts with OsPHR2 and negatively regulates Pi signaling and homeostasis [28]. In this context, non-responsiveness of OsLPR2 to Pi deficiency may not completely rule out its role in Pi sensing and signaling cascade. Increase in the relative expression levels of OsLPR3 and OsLPR4 under both $-\mathrm{P}$ and $-\mathrm{K}$ conditions suggested cross talk between these two nutrients. A similar cross talk between $\mathrm{P}$ and $\mathrm{K}$ was also observed in soybean in which several members of GmPTs, a Pht1 gene family encoding Pi transporters, were upregulated by both $\mathrm{P}$ and $\mathrm{K}$ deficiencies [29]. In another study, a high-density array comprising 1,280 genes from tomato roots revealed coordinated and coregulation of genes encoding transporters of $\mathrm{Pi}$ and $\mathrm{K}$ when deprived of either Pi or K [30]. Furthermore, microarray analysis of the global Pi deficiency response in Arabidopsis revealed significant induction in the expression levels of several genes (KUP10, KUP11, HAK5, KAT1 and KEA2) encoding different $K$ transporters [31]. Suppression and induction in the relative expression of OsLPR1 under $-\mathrm{P}$ and $-\mathrm{Fe}$ conditions, respectively suggested their antagonistic effects on this gene. The result was consistent with an earlier study, which showed that availability of $\mathrm{Pi}$ exerted significant influence on the regulation of Fe-responsive genes in rice [26]. Further, availability of Fe also affects Pi deficiency-mediated morphophysiological and molecular responses in Arabidopsis [31-33]. These studies thus provided evidences of a cross talk between $\mathrm{Pi}$ and $\mathrm{Fe}$ in both rice and Arabidopsis. On the contrary, $-\mathrm{N}$ either exerted attenuating (OsLPR3 and OsLPR5) or no effect (OsLPR1, OsLPR2 and OsLPR4) on the relative expression levels of different members of OsLPRs. Increases in the relative expression levels of OsLPR3 and OsLPR5 under $-\mathrm{P}$ condition and their suppression under $-\mathrm{N}$ condition suggested an incidence of an antagonistic cross talk between these two nutrients in rice. A similar antagonistic cross talk between these two nutrients was evident in rice for a gene encoding sulfate transporter 1.2 (LOC_Os03g09970), which was upand down-regulated in response to $-\mathrm{P}$ and $-\mathrm{N}$ conditions, respectively [34]. There are also growing evidences toward the interactions between $\mathrm{P}$ and $\mathrm{N}$ signaling pathways in Arabidopsis [35-37]. Overall, the study revealed the cross talk across different nutrients, which exerts regulatory influence on $O S L P R$ family members. It is consistent with well established dogma that deficiency of one nutrient can cause imbalance of other nutrients and thereby their related morphophysiological and molecular responses [38]. On the contrary, expression levels of all the members of OsLPRs were not affected during Mg deficiency.

\section{Phosphite represses OsLPR3/5 responses to Pi deficiency in rice}

Phosphite (Phi) is a non-metabolizable analog of Pi. Phi is taken up by plant through Pi transporters, mimics Pi to some extent, interferes with $\mathrm{Pi}$ signaling and have been shown to suppress the coordinated expression of PSR genes in Arabidopsis [39-41]. Phi is thus a potent tool for determining whether a gene is a component of a sensing and signaling network that governs Pi homeostasis. Therefore, to compare the effects of Phi and Pi deficiency treatments on the relative expression levels of OsLPR3/5 in roots, rice seedlings (14-d-old) were grown under $+\mathrm{Pi}(300 \mu \mathrm{M} \mathrm{Pi})$, $-\mathrm{Pi}(0 \mu \mathrm{M} \mathrm{Pi})$ and + Phi/-Pi $(300 \mu \mathrm{M}$ Phi/ $0 \mu \mathrm{M} \mathrm{Pi})$ conditions for $3 \mathrm{~d}$ (Fig. 6a). There were significant increases in
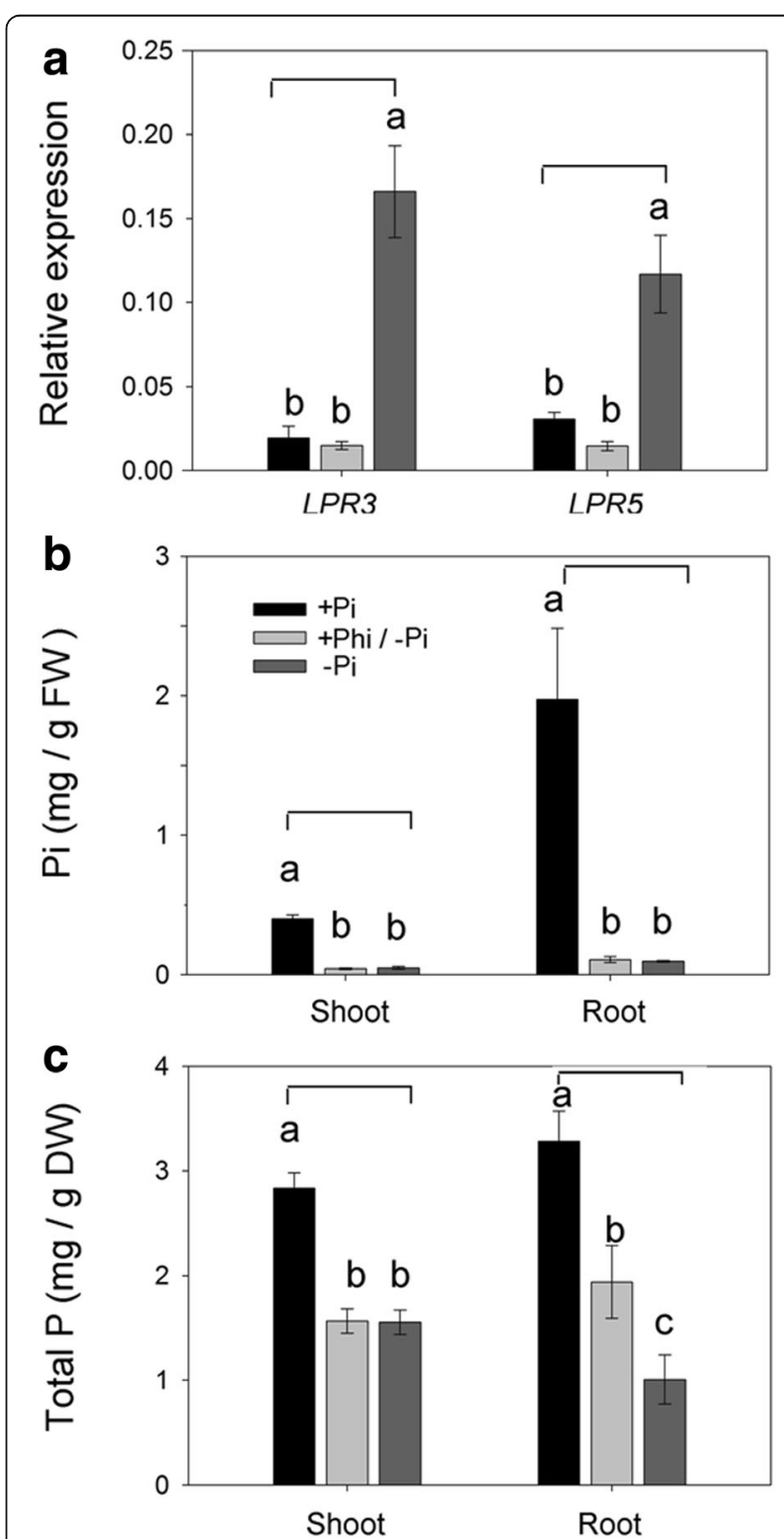

Fig. 6 Phosphite represses the responses of OsLPR3/5 to Pi deficiency. Rice seedlings (14-d-old) were grown under + Pi (300 $\mu \mathrm{M}$ Pi), $-\mathrm{Pi}(0 \mu \mathrm{M}$ Pi) and + Phi/-Pi (300 $\mu \mathrm{M}$ Phi/ $0 \mu \mathrm{M}$ Pi) conditions for $3 \mathrm{~d}$. a qRT-PCR was used for determining the relative expression levels of OsLPR3/5 in the roots. Actin was used as an internal control. Data are presented for b Pi content and $\mathbf{c}$ Total $P$ and values are means $\pm S E(n=3)$ with different letters indicating values that differ significantly $(P<0.05)$ 
the relative expression levels of both OsLPR3/5 in roots of $-\mathrm{Pi}$ seedlings compared with $+\mathrm{Pi}$ seedlings. However, the relative expression levels of these genes in $+\mathrm{Phi} /-\mathrm{Pi}$ roots were significantly attenuated and became almost comparable with $+\mathrm{P}$ seedlings. The results provided evidence towards the involvement of OsLPR $3 / 5$ in Pi deficiency-mediated signal transduction. The results were consistent with an earlier study reporting attenuation in the expression of $\mathrm{Pi}$ starvation-induced OsIPS1 and OsIPS2 in rice upon long-term exposure to Phi [42]. As anticipated, there were significant reductions in the contents of $\mathrm{Pi}$ and total $\mathrm{P}$ in root and shoot of $-\mathrm{Pi}$ seedlings compared with + Pi seedlings (Fig. 6b, c). Significant reductions in the contents of $\mathrm{Pi}$ (shoot and root) and total P (shoot) were also observed in + Phi/-Pi seedlings and the values were comparable with $-\mathrm{Pi}$ seedlings. This suggested that $+\mathrm{Phi} /-\mathrm{Pi}$ and $-\mathrm{Pi}$ treatments treatment exerted similar attenuating influence on Pi content and total P. Notably though, total P content in $+\mathrm{Phi} /-\mathrm{Pi}$ roots was significantly lower and higher compared with $+\mathrm{Pi}$ and $-\mathrm{Pi}$ roots, respectively. The results thus suggested partial influence of Phi on sensing and signaling cascade governing Pi homeostasis.

\section{Short- and long-term effects of Pi deficiency on the ex- pression profiles of OsLPRs in the roots}

Rice seedlings (14-d-old) were subjected to $+\mathrm{Pi}$ and $-\mathrm{Pi}$ conditions for different time intervals $(6 \mathrm{~h}, 1 \mathrm{~d}, 2 \mathrm{~d}, 7 \mathrm{~d}$ and $21 \mathrm{~d})$ and subsequently replenished with $+\mathrm{Pi}(1 \mathrm{~d})$ after $-\mathrm{Pi}(21 \mathrm{~d})$ treatment. An earlier study had reported complete Pi starvation of rice seedlings after $21 \mathrm{~d}$ of $-\mathrm{Pi}$ treatment [43]. High affinity Pi transporter OsPT6 is induced rapidly and sustains induction in both roots and shoots during -Pi treatment [44]. Therefore, OsPT6 is a potent gene for validating the fidelity of the growth conditions used for growing rice seedlings under $+\mathrm{Pi}$ and Pi conditions. qRT-PCR was employed for determining the relative expression levels of OsLPRs (1,3,4 and 5) and OsPT6 in the roots of seedlings grown under $+\mathrm{Pi}$ and $-\mathrm{Pi}$ conditions for different time intervals and upon replenishment with + Pi (Fig. 7). Relative expression levels of OsPT6 induced rapidly during short-term (6 h) -Pi treatment, augmented commensurately during longer durations of this treatment and attenuated rapidly upon replenishment of $\mathrm{Pi}(21 \mathrm{~d})$ seedlings with $+\mathrm{Pi}(1 \mathrm{~d})$. The results provided evidence towards the efficacy of the growth condition being employed in the present study for determining the temporal effects of $-\mathrm{Pi}$ condition on the relative expression profiles of the members of OsLPRs. Compared with $+\mathrm{Pi}$, the relative expression levels of OsLPR1 were significantly attenuated during -Pi treatments for $6 \mathrm{~h}, 2 \mathrm{~d}$ and $7 \mathrm{~d}$ and induced significantly upon replenishment with $+\mathrm{Pi}$. On the contrary, there was a significant increase in the relative expression level of OsLPR3 during short-term $(6 \mathrm{~h})-\mathrm{Pi}$ treatment and its relative expression levels increased concomitantly with an increase in the duration of this treatment compared with $+\mathrm{Pi}$. Although relative expression level of OsLPR5 after short-term (6 h) -Pi treatment was comparable with $+\mathrm{Pi}$, its levels increased significantly during prolonged ( $1 \mathrm{~d}, 2 \mathrm{~d}, 7 \mathrm{~d}$ and $21 \mathrm{~d})$-Pi treatments exhibiting a trend similar to OsLPR3. Many of the PSR genes are known to be induced transiently during short-term -Pi treatment [45]. On the contrary, inductions in the relative expression levels of OsLPR3 and 5 during short-term $(6 \mathrm{~h})-\mathrm{Pi}$ treatment were not transient. In a global microarray analysis of spatiotemporal $-\mathrm{Pi}$ responses of Arabidopsis, several PSR genes involved in Pi acquisition (Pht1;4; [46]), mobilization (RNS1; [47]), phospholipid substitution (SQD2; [48]) and root development (PLDZ2; [49]) also showed a similar pattern of early and sustained induction. There were significant reductions in the relative expression levels of both OsLPR3 and 5 in the roots of $-\mathrm{Pi}$ (21 d) seedlings upon replenishment with $+\mathrm{Pi}(1 \mathrm{~d})$. This provided evidence towards their transcriptional regulation by $\mathrm{Pi}$ availability and their potential roles in the maintenance of Pi homeostasis. Although there were significant increases in the relative expression levels of OsLPR4 during long-term (7 d and $21 \mathrm{~d})-\mathrm{Pi}$ treatments compared with $+\mathrm{Pi}$, subsequent replenishment with $+\mathrm{Pi}$ did not exert any attenuating effect on its elevated relative expression level. This suggested an unlikely role of $\mathrm{Pi}$ in the transcriptional regulation of OsLPR4. Overall, differential relative expression levels of OsLPR1,3,4 and 5 during temporal $-\mathrm{Pi}$ treatments and after replenishment with $+\mathrm{Pi}$ suggested their specific roles in Pi sensing and signaling cascades. It is not surprising because members of a gene family often exhibit lack of functional redundancy. For instance, members of Pi transporter family (OsPTs) in rice exhibit variable responses to $-\mathrm{Pi}$ condition and play diverse roles in maintaining Pi homeostasis [44, 50-53].

\section{Split-root experiment revealed the effect of systemic Pi sensing on the relative expression levels of OsLPR3/5}

Split-root experiment in which each half of the intact root system remains in contact with a different nutrient medium is an attractive technique for determining whether PSR genes are regulated by external Pi availability (local sensing) or by internal Pi status of the whole plant (systemic sensing) [54]. In Arabidopsis, using this technique, an array of PSR genes were identified that were specifically regulated either by local or systemic $\mathrm{Pi}$ sensing [55]. Therefore, in the present study, this technique was employed for determining the effects of local and systemic Pi sensing on the relative expression levels of OsLPR3/5 and total P content in the root of rice seedlings (Fig. 8). In a hydroponic system, both halves of rice root were submerged either in $+\mathrm{P}(300 \mu \mathrm{M} \mathrm{Pi})$ or $-\mathrm{Pi}$ $(0 \mu \mathrm{M} \mathrm{Pi})$ to mimic control plants growing in a 

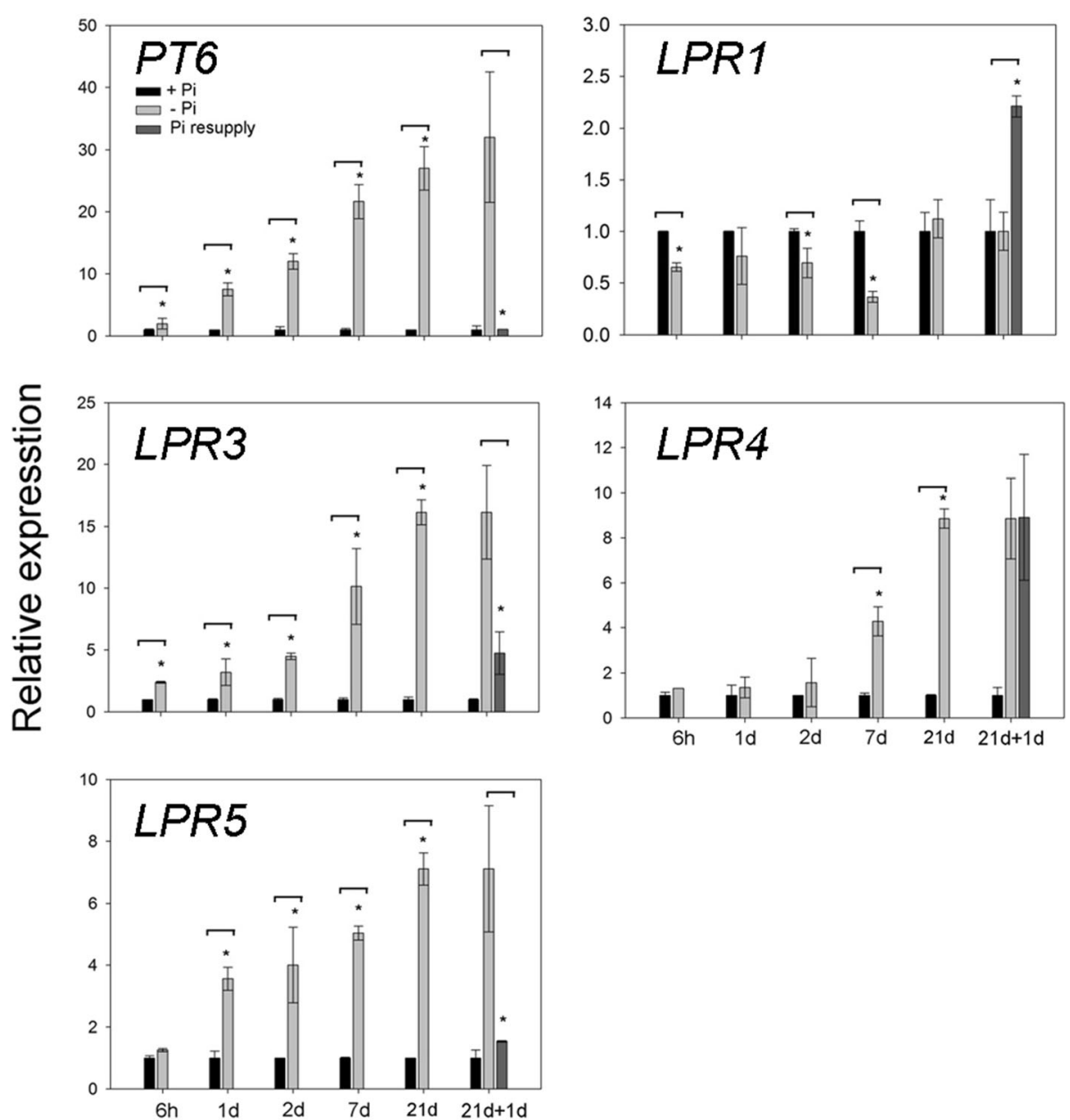

Fig. 7 Short-and long-term effects of Pi deprivation on the expression of OsLPRs in roots. Rice seedlings (14-d-old) were grown under $+P$ $(300 \mu \mathrm{M}$ Pi) and $-\mathrm{P}(0 \mu \mathrm{M} \mathrm{Pi})$ conditions for $6 \mathrm{~h}, 1 \mathrm{~d}, 2 \mathrm{~d}, 7 \mathrm{~d}$ and $21 \mathrm{~d}$. After $21 \mathrm{~d}$ of treatment, half of -P plants were replenished with $+P$ for $1 \mathrm{~d}$. qRT-PCR was used for determining the relative expression levels of $\operatorname{OsLPRs}(1,3,4$ and 5$)$ in root samples. Effects of Pi deprivation on their relative expression levels were also compared with Pi deficiency-induced high affinity Pi transporter OsPT6. Actin was used as an internal control. Values are means $\pm \mathrm{SE}(n=3)$ and asterisk indicates that the values for $-\mathrm{P}$ differ significantly $(P<0.05)$ compared with $+\mathrm{P}$

homogeneous medium and hereafter referred as $\mathrm{c}+\mathrm{P}$ and $\mathrm{c}-\mathrm{P}$, respectively. In another set-up, each half of the intact root system was placed in $+\mathrm{P}$ and $-\mathrm{Pi}$ nutrient media and referred to as $\mathrm{sp}+\mathrm{P}$ and $\mathrm{sp}-\mathrm{P}$, respectively. qRT-PCR was employed for determining the relative expression levels of OsLPR3/5 in the roots of the seedlings grown under $\mathrm{c}+\mathrm{P}, \mathrm{c}-\mathrm{P}, \mathrm{sp}+\mathrm{P}$ and $\mathrm{sp}-\mathrm{P}$ conditions (Fig. 8a). As anticipated, relative expression levels of OsLPR3/5 were significantly higher in the roots of $\mathrm{c}-\mathrm{P}$ compared with $\mathrm{c}+\mathrm{P}$. However, there were significant attenuations in their relative expression levels in $\mathrm{sp}-\mathrm{P}$ roots compared with $\mathrm{c}-\mathrm{P}$ and the values were almost comparable with $\mathrm{c}+\mathrm{P}$. Relative expression levels of OsLPR3/5 were comparable in $\mathrm{c}+\mathrm{P}$ and $\mathrm{sp}+\mathrm{P}$ roots. This clearly suggested that despite the presence of $\mathrm{sp}-\mathrm{P}$ roots in -Pi medium, the expression levels of OsLPR3/5 were regulated systemically by whole plant Pi status. The results were contrary to an earlier study in Arabidopsis in which LPR1 and LPR2 were shown to play pivotal roles in local Pi sensing-mediated responses of PRG [6]. This suggested functional divergence of $L P R$ family in taxonomically diverse Arabidopsis and rice. Root tissues were also analyzed for the total P content (Fig. 8b). Total $\mathrm{P}$ content was highest and lowest in $\mathrm{c}+\mathrm{P}$ and $\mathrm{c}-\mathrm{P}$ roots, respectively. Interestingly though, differences in the total $\mathrm{P}$ content in $\mathrm{sp}+\mathrm{P}$ and $\mathrm{sp}-\mathrm{P}$ were statistically insignificant. Variable total P content in these root tissues correlated with the OsLPR3/5 expression levels in them.

\section{OsLPR3/5 are negatively regulated by $O s P H R 2$ and are influenced by SIZ1/PHO2/SPX1-mediated Pi sensing} In rice, several transcription factors (TFs) have been identified that play pivotal roles in the transcriptional regulation of PSR genes $[3,17,56]$. Among these TFs, 


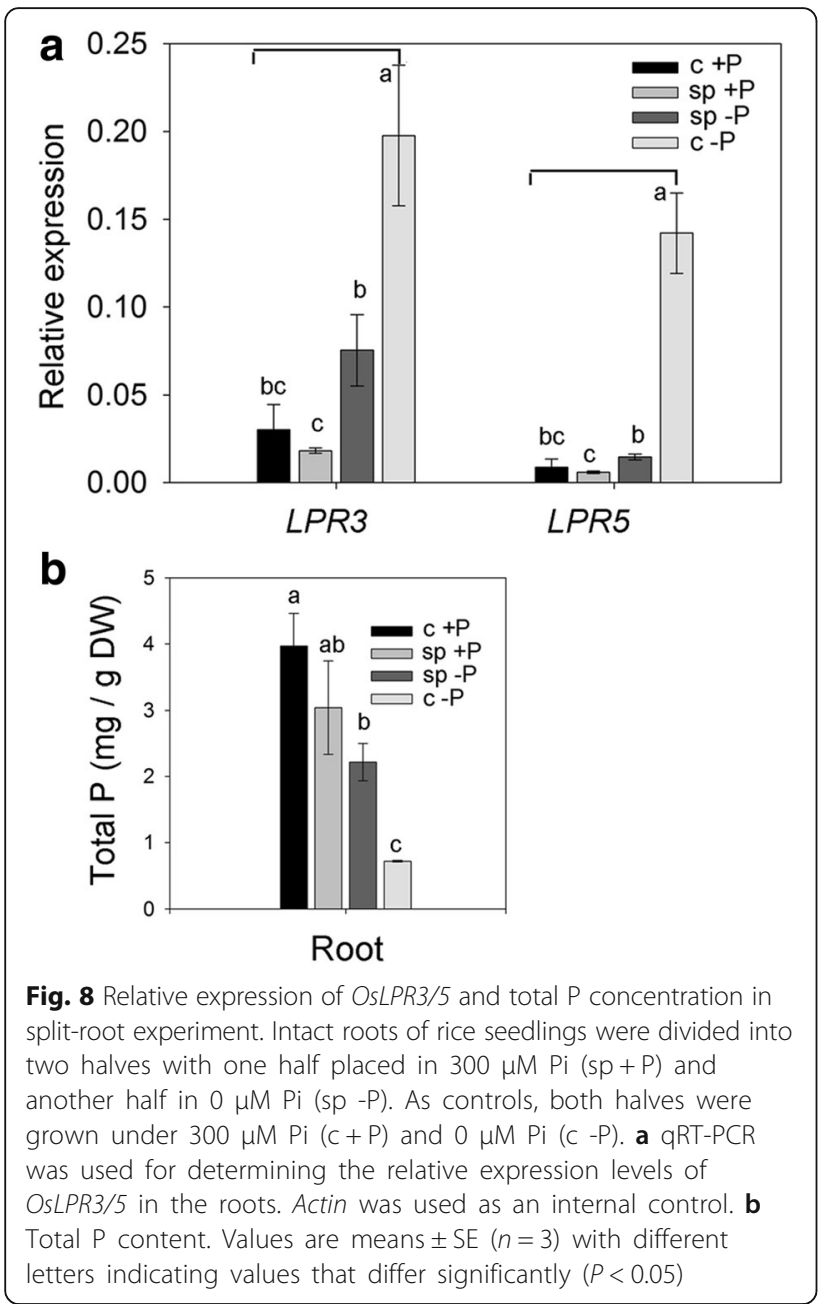

OsPHR2 is expressed constitutively under different Pi regime and has been implicated in regulating Pi signaling and homeostasis $[18,19]$. To determine whether OsPHR2 exerts any regulatory influence on OsLPRs, their relative expression levels were assayed in the roots of the wildtype (ZH11) and osphr2 seedlings grown under $+\mathrm{P}$ and $-\mathrm{P}$ conditions (Fig. 9a). There were significant increases in the relative expression levels of OSLPR3 and 5 in the roots of osphr 2 under both $+\mathrm{P}$ and $-\mathrm{P}$ conditions compared with their corresponding wild types. However, marginal but significant increase in the relative expression of OsLPR4 was detected in the roots of osphr2 compared with the wild type only under $+\mathrm{P}$ condition. Further, relative expression levels of OsLPR3/4/5 were compared in $+\mathrm{P}$ and $-\mathrm{P}$ roots of OsPHR2-Ox plants and their corresponding wild types (Fig. 9b). Although relative expression levels of OsLPR3 and OsLPR5 were significantly attenuated in $+\mathrm{P}$ and $-\mathrm{P}$ roots of OsPHR2-Ox plants compared with their corresponding wild types, no such effect was detected in the relative expression levels of OsLPR4. This suggested a more pronounced negative regulatory influence of OsPHR2 on the expression of OsLPR3 and 5 than on OsLPR4. Interestingly though, the promoter of OsLPR4 is enriched with P1BS motif, while those of other OsLPRs (1-3) are enriched with W-box motif (Additional file 7). In a global microarray analysis of Pi deficiency responses in Arabidopsis, promoters of the PSR genes were analyzed for the presence of P1BS motif(s) [31]. The analysis revealed enrichment of the promoters of several PSR genes with P1BS motif(s). In addition, several genes were also identified that were not induced under $-\mathrm{P}$ condition despite the presence of this motif. For instance, promoters of genes encoding purple acid phosphatase (PAP) 19 (At3g46120) and 20 (At3g52780) are enriched with 3 P1BS motifs each but neither of them shows any induction during Pi deficiency. In this context, it is not surprising to observe lack of any significant effect of either mutation $(-\mathrm{P})$ or overexpression $(+\mathrm{P}$ and $-\mathrm{P})$ of OsPHR2 on the relative expression levels of OsLPR4. However, lack of P1BS motif(s) on the promoters of OsLPR3/5 suggested their negative regulation by OsPHR2 by possibly invoking a feed-forward regulatory loop (FFRL). In Arabidopsis, TFs NAM/ATAF1/2/ CUC2016 (NAC016; At1g34180) and NAC-LIKE, ACTIVATED BY AP3/PI (NAP; At1g69490) repress the transcription of ABSCISIC ACID-RESPONSIVE ELEMENT BINDING PROTEIN1 (AREB1; At1g45249) through a FFRL [57]. Presence of two W-box in the promoter of OsLPR3 (Additional file 7) suggested a likely regulatory influence of WRKY TFs. In rice, WRKY TF superfamily comprises 109 members [58]. Recent study has shown the role of OsWRKY74 in regulating Pi homeostasis [59]. Therefore, it would be intriguing to investigate whether OsWRKY74 and OsPHR2 regulate OsLPR3 in a FFRL, which warrants further studies.

Transcript levels of OsSPX1 induced in -P root and stem and also in OsPHR2-Ox plants suggesting the former to be downstream of the latter [60]. Another study demonstrated the inhibition in the activity of OsPHR2 by OsSPX1 in a Pi-dependent manner [22]. Together these studies suggested a negative feedback loop regulation of OsPHR2 by OsSPX1. Since the relative expression levels of OsLPR3 and OsLPR5 were significantly increased in osphr2 under both $+\mathrm{P}$ and $-\mathrm{P}$ conditions (Fig. 9a), a similar expression pattern was anticipated in SPX1-Ox. Consistent with this assumption, significant increases in the relative expression levels of OSLPR3 and OsLPR5 were observed in SPX1-Ox under both $+\mathrm{P}$ and $-\mathrm{P}$ conditions compared with their corresponding wild types (Fig. 9c). On the contrary, relative expression levels of OsLPR4 in SPX1-Ox $(+\mathrm{P}$ and $-\mathrm{P})$ were comparable with the wild type. This suggested that OsLPR3 and OsLPR5 are part of OsPHR2-OsSPX1-mediated regulation of $\mathrm{Pi}$ homeostasis.

OsPHO2, a signaling component downstream of OsPHR2, plays a key role in regulating the expression of 


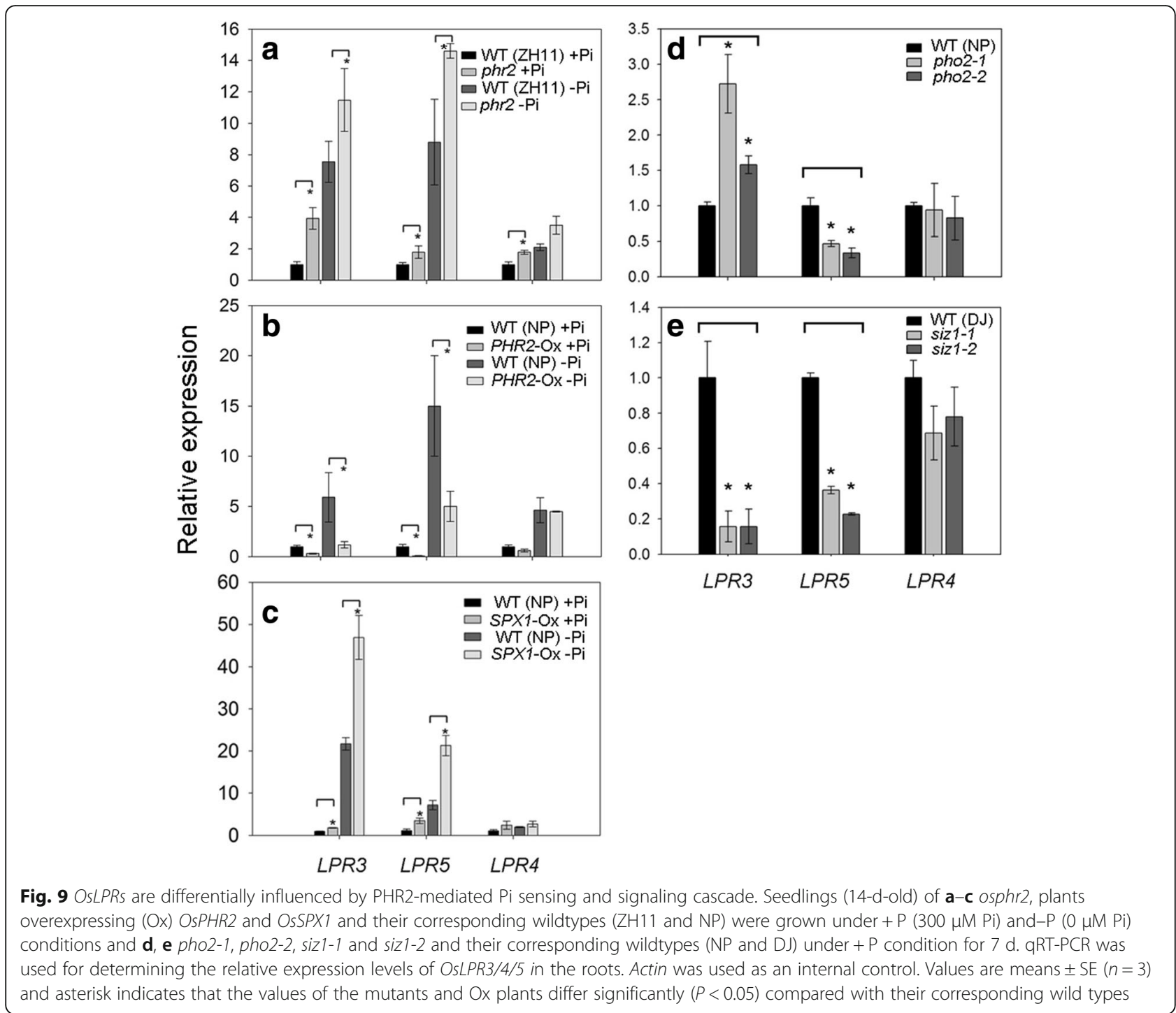

OsPTs and multiple Pi starvation responses thereby influencing Pi utilization in rice $[20,21]$. Therefore, the regulatory influence of OsPHO2 on OsLPR3-5 was investigated (Fig. 9d). There were significant increases in the relative expression levels of OsLPR3 in pho2-1 and pho22 compared with the wild type. An increased expression of OsSPX1 in the roots of pho2 mutant suggested a negative regulatory influence of $\mathrm{OsPHO} 2$ on its downstream OsSPX1 [60]. The accentuated relative expression levels of OSLPR3 in SPX1-Ox (Fig. 9c) and pho2-1 and pho2-2 (Fig. 9d) thus suggested it to be downstream of OsPHR2-OsPHO2-OsSPX1 pathway. On the contrary, significant reductions and no effect on the relative expression levels of OsLPR5 and OsLPR4, respectively in pho2-1 and pho2-2 compared with the wild type (Fig. 9d) highlighted differential roles of the members of OsLPR family in OsPHR2-OsPHO2-OsSPX1-mediated Pi sensing.
Sumoylation is a critical post-translational modification involved in protein-protein interaction, transcriptional activation and localization of proteins [61]. OsSIZ1 and OsSIZ2, homologs of Arabidopsis SIZ1 in rice, partially complemented the morphological phenotype of siz1-2 in Arabidopsis [62]. Further, several genes involved in Pi sensing and signaling were modulated in ossiz1 [63]. Therefore, the effects of OsSIZ1 on the regulation of OsLPR3-5, were assayed (Fig. 9e). Significant reductions were observed in the relative expression levels of OsLPR3 and OsLPR5 in both siz1-1 and siz1-2 compared with the wild-type. Although marginal reductions in the expression levels of OsLPR4 were also detected in these mutants, the values were statistically insignificant. This suggested a posttranslational regulatory influence of OsSIZ1 on OsLPR3 and OsLPR5. However, at present it is not known whether OsSIZ1 exerts direct regulatory influence on OsLPR3 and OsLPR5 by sumoylating them or mediated through a target, 
which is yet to be identified. Functional characterization of OsLPRs could provide an insight into their specific roles in maintaining $\mathrm{Pi}$ homeostasis and thus warrants further studies.

\section{Conclusion}

This study presented a detailed genome-wide analysis of the gene structure, phylogenetic evolution and tissuespecific expression patterns of LPR family members in rice (OsLPR1- OsLPR5). Phylogenetic analysis revealed their grouping into two distinct subclades. Differential expression of these genes under deficiencies of $\mathrm{Pi}$ and other nutrients suggested lack of functional redundancy across them. Further an insight into the likely roles of OsLPR3 and OsLPR5 in the maintenance of Pi homeostasis was gained by assaying their relative expression levels in lossof-function mutants (ossiz1, osphr2 and ospho2) and transgenic rice overexpressing either OsPHR2 or OsSPX1. The results from this study thus provide a basis for further detailed functional characterization of different members of OSLPR family for elucidation of their specific roles in maintaining homeostasis during deficiency of $\mathrm{Pi}$ and/or other nutrients.

\section{Methods}

Database searches, sequence alignment and phylogenetic analysis

Complete genomic sequence and transcripts of OsLPR1-5 were retrieved from Michigan State University (MSU) Rice Genome Annotation Project assembly (v7) (http://rice. plantbiology.msu.edu/). Identification of LPR homologs was performed using tBLASTn program and PLAZA1.0 database (http://bioinformatics.psb.ugent.be/plaza/). LPR homologs were identified in dicots (Arabidopsis thaliana, Capsella rubella, Carica papaya, Cicer arietinum, Cucumis sativus, Fragaria vesca, Glycine max, Lotus japonicus, Malus domestica, Manihot esculenta, Populus trichocarpa, Prunus persica, Ricinus communis, Solanum lycopersicum, Theobroma cacao and Vitis vinifera), monocots (Aegilop stauschii, Brachypodium distachyon, Hordeum vulgare, Oryza sativa, Setaria italica, Sorghum bicolor, Triticum urartu and Zea mays), gymnosperms (Picea sitchensis and Selaginella moellendorffii), bryophytes (Physcomitrella patens) and chlorophyta (Volvox carteri and Chlamydomonas reinhardtii). The unrooted phylogenetic tree of $L P R$ homologs was made using the neighbor-joining method and displayed using the MEGA4.0 program.

\section{Plant materials and growth conditions}

In the present study, wild type rice (Oryza sativa) ssp. japonica varieties (Nipponbare, ZH11 and Dongjin), T-DNA insertion mutants (ospho2-1/2 [21], ossiz1-1/2 [63], osphr2 [64] in the backgrounds of Nipponbare, Dongjin and ZH11, respectively) and two homozygous overexpresors
(OsSPX1-Ox [60] and OsPHR2-Ox [Gu unpublished work] in Nipponbare background) were used. For OsPHR2 overexpressors, the ORF of OsPHR2 was amplified using the specific primers from Nipponbare cDNA. The PCR product was ligated into the pTCK303 vector as described [44]. By electroporation, the construct was transferred to Agrobacterium tumefaciens strain EHA105 and then transformed into Nipponbare as described [65]. For hydroponic experiments, rice seeds were surface-sterilized for 1 min with $75 \%$ ethanol (v/v) and for 30 min with diluted $(1: 3, \mathrm{v} / \mathrm{v}) \mathrm{NaClO}$ followed by thorough rinsing for $30 \mathrm{~min}$ with deionized water. Seeds were germinated in dark at $25{ }^{\circ} \mathrm{C}$ for $3 \mathrm{~d}$. The hydroponic experiments were carried out in a growth room with a 16 -h-light $\left(30{ }^{\circ} \mathrm{C}\right) / 8$-h-dark $\left(22{ }^{\circ} \mathrm{C}\right)$ photoperiod and the relative humidity was maintained at approximately $70 \%$. Uniformly grown seedlings (7-d-old) were then transferred to complete nutrient solu-

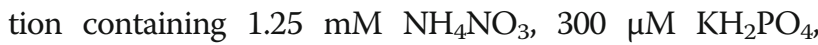
$0.35 \mathrm{mM} \mathrm{K} \mathrm{SO}_{4}, 1 \mathrm{mM} \mathrm{CaCl} \cdot 2 \mathrm{H}_{2} \mathrm{O}, 1 \mathrm{mM} \mathrm{MgSO} 4$. $7 \mathrm{H}_{2} \mathrm{O}, 0.5 \mathrm{mM} \mathrm{Na}_{2} \mathrm{SiO}_{3} \cdot 9 \mathrm{H}_{2} \mathrm{O}, 20 \mu \mathrm{M}$ Fe-EDTA, $20 \mu \mathrm{M}$ $\mathrm{H}_{3} \mathrm{BO}_{3}, 9 \mu \mathrm{M} \mathrm{MnCl} \cdot 4 \mathrm{H}_{2} \mathrm{O}, 0.32 \mu \mathrm{M} \mathrm{CuSO}_{4} \cdot 5 \mathrm{H}_{2} \mathrm{O}$, $0.77 \mu \mathrm{M} \mathrm{ZnSO} \cdot \cdot 7 \mathrm{H}_{2} \mathrm{O}$ and $0.39 \mu \mathrm{M} \mathrm{Na}_{2} \mathrm{MoO}_{4} \cdot 2 \mathrm{H}_{2} \mathrm{O}$. For $+\mathrm{P}$ (control) and $-\mathrm{P}$ media, $\mathrm{KH}_{2} \mathrm{PO}_{4}$ concentrations used were $300 \mu \mathrm{M}$ and $0 \mu \mathrm{M}$, respectively. To maintain equimolar concentration of $\mathrm{K}$ in $+\mathrm{P}$ and $-\mathrm{P}$ media, $\mathrm{KH}_{2} \mathrm{PO}_{4}$ in $+\mathrm{P}$ medium was replaced with $\mathrm{K}_{2} \mathrm{SO}_{4}$ in $-\mathrm{P}$ medium. For $+\mathrm{K}$ (control) and $-\mathrm{K}$ media, $300 \mu \mathrm{M} \mathrm{KH}_{2} \mathrm{PO}_{4}$ and $300 \mu \mathrm{M} \mathrm{NaH} \mathrm{PO}_{4}$ were used, respectively. For $+\mathrm{Mg}$ (control) and $-\mathrm{Mg}$ media, $1 \mathrm{mM} \mathrm{MgSO}{ }_{4} \cdot 7 \mathrm{H}_{2} \mathrm{O}$ and $1 \mathrm{mM}$ $\mathrm{Na}_{2} \mathrm{SO}_{4} \cdot 7 \mathrm{H}_{2} \mathrm{O}$ were used, respectively. For $-\mathrm{Fe}$ medium, $20 \mu \mathrm{M}$ Fe-EDTA was eliminated from $+\mathrm{Fe}$ (control) medium. Deionized water was used throughout the experiments and $\mathrm{pH}$ of all the nutrient solutions were adjusted to 5.0. For all the experiments, nutrient solutions in the hydroponic set up were refreshed every $3 r d$ d. For Pi splitroot experiment, seedlings were prepared and grown in complete nutrient solution for $14 \mathrm{~d}$, and then transferred to split-root container for $14 \mathrm{~d}$. The roots of individual plants were separated into two equal parts, placed into separate containers such that one half received $300 \mu \mathrm{M} \mathrm{Pi}$, while the other half did not receive any Pi. The controls included a split-root treatment in which both halves of the roots received $+\mathrm{Pi}(300 \mu \mathrm{M} \mathrm{Pi})$ and $-\mathrm{P}(0 \mu \mathrm{M} \mathrm{Pi})$. For Phi treatment, seedlings were grown in $-\mathrm{Pi}(0 \mu \mathrm{M} \mathrm{Pi})$ for $21 \mathrm{~d}$. Uniformly grown seedlings were then transferred to $+\mathrm{Pi}$ $(300 \mu \mathrm{M}$ Pi $),-\mathrm{Pi}(0 \mu \mathrm{M}$ Pi) and + Phi/-Pi $(300 \mu \mathrm{M}$ Phi, $0 \mu \mathrm{M}$ Pi) solutions for $3 \mathrm{~d}$.

\section{qRT-PCR}

Total RNAs from various tissues were isolated using Trizol reagent (Invitrogen) and first-strand cDNA was synthesized with an oligo (dT)-18 primer and reverse transcriptase. OsActin (accession no. AB047313) was used as an internal control for qRT-PCR analysis. qRT- 
PCR analysis was performed using SYBR green master mix (Vazyme) and ABI StepOnePlus Sequence Detection System (Applied Biosystems), from biological triplicates. Primers used for qRT-PCR are listed in Additional file 8.

\section{Measurements of $\mathrm{Pi}$ and total $\mathrm{P}$ concentrations in plants} To measure Pi concentration in plants, about $0.5 \mathrm{~g}$ Fresh sample was used for the quantification of Pi concentration in plants as described [18]. Total $\mathrm{P}$ concentration was quantified by digesting dry sample $(0.05 \mathrm{~g})$ with $\mathrm{H}_{2} \mathrm{SO}_{4}$ $\mathrm{H}_{2} \mathrm{O}_{2}$ at $280{ }^{\circ} \mathrm{C}$ followed by assay with molybdenum blue as described [66].

\section{Statistical analysis}

Data were analyzed by analysis of variance (ANOVA) using the SPSS 13 program. Different letters or asterisks on the histograms between the mutants and the WT and/or different treatments indicate their statistically significant difference using Duncan multiple range test at $P<0.05$.

\section{Additional files}

Additional file 1: Details of locus ID, cDNA accession number and protein characteristics of the members of OsLPR gene family. (DOC $33 \mathrm{~kb}$ ) Additional file 2: Schematic figure showing positions of OSLPRT-5 on rice chromosome1. (DOC $84 \mathrm{~kb}$ )

Additional file 3: Analysis of domain structure of LPRs in diverse plant species. (DOC $101 \mathrm{~kb}$ )

Additional file 4: Phylogenetic analysis of the members of MCO family in rice. (DOC $288 \mathrm{~kb}$ )

Additional file 5: Alignment of amino acid sequences of LPR proteins in rice and Arabidopsis. (DOC $390 \mathrm{~kb}$ )

Additional file 6: OsLPRs exhibited tissue-specific expression. (DOC $75 \mathrm{~kb}$ ) Additional file 7: Cis-elements in the promoters of OsLPRs. (DOC $78 \mathrm{~kb}$ ) Additional file 8: Primers used for qRT-PCR analysis of OsLPRsand OsPT6. (DOC $32 \mathrm{~kb}$ )

\section{Abbreviations}

AREB1, ABSCISIC ACID-RESPONSIVE ELEMENT BINDING PROTEIN1; Fe, iron; FFRL, feed-forward regulatory loop; K, Potassium; LTN1, LEAF TIP NECROSIS1; LPR1, low phosphate root1; Ipsi, local phosphate sensing impaired; Mg, magnesium; MCOs, multicopper oxidases; MSU, Michigan State University; N, nitrogen; NAC016, NAM/ATAF1/2/CUC2016; NAP, NAC-LIKE, ACTIVATED BY AP3/PI; NCBI, National Center for Biotechnology Information; Ox, overexpressing; P, phosphorus: Pi, phosphate; Phi, phosphite; -P, Pi deficiency; P1BS, PHR1-binding sequence; PSR, Pi starvation-responsive; PRG, primary root growth; PAP, purple acid phosphatase; SUMO, small ubiquitin-like modifier; qRT-PCR, quantitative real-time PCR; QTLs, quantitative trait loci; SI, sequence identity; TF, transcription factor; TNC, trinuclear Cu cluster; UTR, untranslated region

\section{Acknowledgments}

This work was supported by the Chinese National Natural Science Foundation (31172014), the National Program on R\&D of Transgenic Plants (2014ZX08 009-003-005, 2014ZX0800931B and 2016ZX08009-003-005), the Jiangsu Provincial Natural Science Foundation (BK20141367), the Innovative Research Team Development Plan of the Ministry of Education (IRT1256) and the 111 Project (number 12009). We also thank the Ministry of Science and Technology, Department of Biotechnology, Government of India for awarding Ramalingaswamy Fellowship to A.J. [BT/HRD/35/02/26/2009]. We also acknowledge Viswanathan Satheesh for his valuable suggestions and correction during the preparation and revision of this manuscript.

Availability of data and materials

All the data supporting the present findings is contained within the manuscript.

\section{Authors' contributions}

YC participated in planning and conducting the experiments, did bioinformatics analysis and helped in writing the manuscript. HA carried out some experiments. AJ participated in analysis of the data, and helped in writing the manuscript. XW, LZ and WP participated in carrying out different experiments. AC helped in bioinformatics analysis. GX participated in planning the study. SS conceived the study, participated in planning and analysis of the data, and helped in writing the manuscript. All authors read and approved the final manuscript.

\section{Competing interests}

The authors declare that they have no competing interests.

\section{Consent for publication}

Not applicable.

Ethics approval and consent to participate

Not applicable.

\section{Author details}

${ }^{1}$ State Key Laboratory of Crop Genetics and Germplasm Enhancement, Key Laboratory of Plant Nutrition and Fertilization in Low-Middle Reaches of the Yangtze River, Ministry of Agriculture, Nanjing Agricultural University, Nanjing 210095, China. ${ }^{2}$ National Research Centre on Plant Biotechnology, Lal Bahadur Shastri Building, Pusa Campus, New Delhi 110012, India. ${ }^{3}$ State Key Laboratory of Crop Genetics and Germplasm Enhancement, Key Laboratory of Plant Nutrition and Fertilization in Low-Middle Reaches of the Yangtze River, Ministry of Agriculture, College of Resources and Environmental Science, Nanjing Agricultural University, Nanjing 210095, China.

Received: 21 February 2016 Accepted: 14 July 2016

Published online: 03 October 2016

\section{References}

1. Raghothama KG. Phosphate acquisition. Annu Rev Plant Physiol Plant Mol Biol. 1999;50:665-93.

2. Veneklaas EJ, Lambers H, Bragg J, Finnegan PM, Lovelock CE, Plaxton WC, Price CA, Scheible WR, Shane MW, White PJ, et al. Opportunities for improving phosphorus-use efficiency in crop plants. New Phytol. 2012;195:306-20.

3. López-Arredondo DL, Leyva-González MA, González-Morales SI, López-Bucio J, Herrera-Estrella L. Phosphate nutrition: improving low-phosphate tolerance in crops. Annu Rev Plant Biol. 2014;65:95-123.

4. Sánchez-Calderón L, López-Bucio J, Chacón-López A, Cruz-Ramírez A, Nieto-Jacobo F, Dubrovsky JG, Herrera-Estrella L. Phosphate starvation induces a determinate developmental program in the roots of Arabidopsis thaliana. Plant Cell Physiol. 2005;46:174-84.

5. Reymond M, Svistoonoff S, Loudet O, Nussaume L, Desnos T. Identification of QTL controlling root growth response to phosphate starvation in Arabidopsis thaliana. Plant Cell Environ. 2006;29:115-25.

6. Svistoonoff S, Creff A, Reymond M, Sigoillot-Claude C, Ricaud L, Blanchet A, Laurent Nussaume L, Thierry DT. Root tip contact with low-phosphate media reprograms plant root architecture. Nat Genet. 2007;39:792-6.

7. Narayanan A, Reddy BK. Effect of phosphorus deficiency on the form of plant root system. In: Scaife A, editor. Plant nutrition, vol. 2. Slough: Commonwealth Agricultural Bureau; 1982. p. 412-7.

8. Mollier A, Pellerin S. Maize root system growth and development as influenced by phosphorus deficiency. J Exp Bot. 1999;50:487-97.

9. Shimizu A, Yanagihara S, Kawasaki S, Ikehashi H. Phosphorus deficiencyinduced root elongation and its QTL in rice (Oryza sativa L.). Theor Appl Genet. 2004;109:1361-8.

10. Yi KK, Wu ZC, Zhou J, Du LM, Guo LB, Wu YR, Wu P. OsPTF1, a novel transcription factor involved in tolerance to phosphate starvation in rice. Plant Physiol. 2005;138:2087-96. 
11. Miura K, Rus A, Sharkhuu A, Yokoi S, Karthikeyan AS, Raghothama KG, Baek D, Koo YD, Jin JB, Bressan RA, et al. The Arabidopsis SUMO E3 ligase SIZ1 controls phosphate deficiency responses. Proc Natl Acad Sci U S A. 2005:102:7760-5.

12. Rubio V, Linhares F, Solano R, Martin AC, Iglesias J, Leyva A, Paz-Ares J. A conserved MYB transcription factor involved in phosphate starvation signaling both in vascular plants and in unicellular algae. Gene Dev. 2001;15:2122-33.

13. Bari R, Pant BD, Stitt M, Scheible WR. PHO2, microRNA399, and PHR1 define a phosphate-signaling pathway in plants. Plant Physiol. 2006;141:988-99.

14. Franco-Zorrilla JM, Valli A, Todesco M, Mateos I, Puga MI, Rubio-Somoza I, Leyva A, Weigel D, García JA, Javier Paz-Ares J. Target mimicry provides a new mechanism for regulation of microRNA activity. Nat Genet. 2007;39:1033-7.

15. Puga MI, Mateosa I, Charukesi R, Wang ZY, Franco-Zorrilla JM, de Lorenzo L, Irigoyen ML, Masiero S, Bustos R, Rodríguez J, et al. SPX1 is a phosphatedependent inhibitor of phosphate starvation response1 in Arabidopsis. Proc Natl Acad Sci U S A. 2014;111:14947-52.

16. Gamuyao R, Chin JH, Pariasca-Tanaka J, Pesaresi P, Catausan S, Dalid C, Slamet-Loedin I, Tecson-Mendoza EM, Wissuwa M, Heuer S. The protein kinase Pstol 1 from traditional rice confers tolerance of phosphorus deficiency. Nature. 2012;488:535-9.

17. Wu P, Shou HX, Xu GH, Lian XM. Improvement of phosphorus efficiency in rice on the basis of understanding phosphate signaling and homeostasis. Curr Opin Plant Biol. 2013;16:205-12.

18. Zhou J, Jiao FC, Wu ZC, Li YY, Wang XM, He XW, Zhong WQ, Wu P. OsPHR2 is involved in phosphate-starvation signaling and excessive phosphate accumulation in shoots of plants. Plant Physiol. 2008;146:1673-86.

19. Guo MN, Ruan WY, Li CY, Huang FL, Zeng M, Liu YY, Yu YN, Ding XM, Wu $Y R$, Wu ZC, et al. Integrative comparison of the role of the phosphate responses 1 subfamily in phosphate signaling and homeostasis in rice. Plant Physiol. 2015;168:1762-76.

20. Hu B, Zhu CG, Li F, Tang JY, Wang YQ, Lin AH, Liu LC, Che RH, Chu CC. LEAF TIP NECROSIS1 plays a pivotal role in the regulation of multiple phosphate starvation responses in rice. Plant Physiol. 2011;156:1101-15.

21. Cao Y, Yan Y, Zhang F, Wang HD, Gu M, Wu XR, Sun SB, Xu GH. Fine characterization of $\mathrm{Os} \mathrm{PHO} 2$ knockout mutants reveals its key role in $\mathrm{Pi}$ utilization in rice. J Plant Physiol. 2014;171:340-8.

22. Wang ZY, Ruan WY, Shi J, Zhang L, Xiang D, Yang C, Li CY, Wu ZC, Liu Y, Yu YA, et al. Rice SPX1 and SPX2 inhibit phosphate starvation responses through interacting with PHR2 in a phosphate-dependent manner. Proc Natl Acad Sci U S A. 2014;111:14953-8.

23. Solomon El, Augustine AJ, Yoon J. $\mathrm{O}_{2}$ reduction to $\mathrm{H}_{2} \mathrm{O}$ by the multicopper oxidases. Dalton Trans. 2008;30:3921-32.

24. Müller J, Toev T, Heisters M, Teller J, Moore KL, Hause G, Dinesh DC, Bürstenbinder K, Abel S. Iron-dependent callose deposition adjusts root meristem maintenance to phosphate availability. Dev Cell. 2015;33:216-30.

25. Coudert $Y$, Périn C, Courtois B, Khong NG, Gantet $P$. Genetic control of root development in rice, the model cereal. Trends Plant Sci. 2010;15:219-26.

26. Zheng L, Huang F, Narsai R, Wu J, Giraud E, He F, Cheng L, Wang F, Wu P, Whelan J, et al. Physiological and transcriptome analysis of iron and phosphorus interaction in rice seedlings. Plant Physiol. 2009;151:262-74.

27. Wang Z, Hu H, Huang HJ, Duan K, Wu ZC, Wu P. Regulation of OsSPX1 and OsSPX3 on expression of OsSPX domain genes and Pi-starvation signaling in rice. J Integr Plant Biol. 2009;51:663-74.

28. Lv Qd, Zhong Yj, Wang Yg, Wang Zy, Zhang L, Shi J, Wu Zc, Liu Y, Mao $\mathrm{Cz}$, Yi Kk, Wu P. SPX4 negatively regulates phosphate signaling and homeostasis through Its interaction with PHR2 in rice. Plant Cell. 2014;26:1586-97.

29. Qin L, Guo YX, Chen LY, Liang RK, Gu M, Xu GH, Zhao J, Walk T, Liao H. Functional characterization of 14 Pht1 family genes in yeast and their expressions in response to nutrient starvation in soybean. PLoS One. 2012; 7 , e47726.

30. Wang YH, Garvin DF, Kochian LV. Rapid induction of regulatory and transporter genes in response to phosphorus, potassium, and iron deficiencies in tomato roots: evidence for cross talk and root/ rhizosphere-mediated signals. Plant Physiol. 2002;130:1361-70.

31. Misson J, Raghothama KG, Jain A, Jouhet J, Block MA, Bligny R, Ortet P, Creff A, Somerville $\mathrm{S}$, Rolland N, et al. A genome-wide transcriptional analysis using Arabidopsis thaliana Affymetrix gene chips determined plant responses to phosphate deprivation. Proc Natl Acad Sci U S A. 2005;102:11934-9.
32. Ward JT, Lahner B, Yakubova E, Salt DE, Raghothama KG. The effect of iron on the primary root elongation of Arabidopsis during phosphate deficiency. Plant Physiol. 2008;147:1181-91.

33. Rai V, Sanagala R, Sinilal B, Yadav S, Sarkar AK, Dantu PK, Jain A. Iron availability affects phosphate deficiency-mediated responses, and evidence of cross-talk with auxin and zinc in Arabidopsis. Plant Cell Physiol. 2015;56:1107-23.

34. Cai HM, Xie WB, Lian XM. Comparative analysis of differentially expressed genes in rice under nitrogen and phosphorus starvation stress conditions. Plant Mol Biol Rep. 2013;31:160-73.

35. Kant S, Peng M, Rothstein SJ. Genetic regulation by NLA and MicroRNA827 for maintaining nitrate-dependent phosphate homeostasis in Arabidopsis. PLoS Genet. 2011;7, e1002021.

36. Cerutti T, Delatorre CA. Nitrogen and phosphorus interaction and cytokinin: responses of the primary root of Arabidopsis thaliana and the pdr1 mutant. Plant Sci. 2013:198:91-7.

37. Medici A, Marshall-Colon A, Ronzier E, Szponarski W, Wang R, Gojon A, Crawford NM, Ruffel S, Coruzzi GM, Krouk G. AtNIGT1/HRS1 integrates nitrate and phosphate signals at the Arabidopsis root tip. Nat Commun. 2015;6:6274-84

38. Schachtman DP, Shin R. Nutrient sensing and signaling: NPKS. Annu Rev Plant Biol. 2007:58:47-69.

39. Ticconi CA, Delatorre CA, Abel S. Attenuation of phosphate starvation responses by phosphite in Arabidopsis. Plant Physiol. 2001;127:963-72.

40. Varadarajan DK, Karthikeyan AS, Matilda PD, Raghothama KG. Phosphite, an analog of phosphate, suppresses the coordinated expression of genes under phosphate starvation. Plant Physiol. 2002;129:1232-40.

41. Jost R, Pharmawati M, Lapis-Gaza HR, Rossig C, Berkowitz O, Lambers H, Finnegan PM. Differentiating phosphate-dependent and phosphateindependent systemic phosphate-starvation response networks in Arabidopsis thaliana through the application of phosphite. J Exp Bot. 2015;66:2501-14

42. Hou XL, Wu P, Jiao FC, Jia QJ, Chen HM, Yu J, Song XW, Yi KK. Regulation of the expression of OsIPS1 and OsIPS2 in rice via systemic and local Pi signalling and hormones. Plant Cell Environ. 2005;28:353-64.

43. Secco $D$, Jabnoune $M$, Walker $H$, Shou $H$, Wu $P$, Poirier $Y$, Whelan J. Spatio-temporal transcript profiling of rice roots and shoots in response to phosphate starvation and recovery. Plant Cell. 2013;25: 4285-304.

44. Ai PH, Sun SB, Zhao JN, Fan XR, Xin WJ, Guo Q, Yu L, Shen QR, Wu P, Miller AJ, et al. Two rice phosphate transporters, OsPht1;2 and OsPht1;6, have different functions and kinetic properties in uptake and translocation. Plant J. 2009;57:798-809.

45. Hammond JP, Bennett MJ, Bowen HC, Broadley MR, Eastwood DC, May ST, Rahn C, Swarup R, Woolaway KE, White PJ. Changes in gene expression in Arabidopsis shoots during phosphate starvation and the potential for developing smart plants. Plant Physiol. 2003;132:578-96.

46. Shin H, Shin HS, Dewbre GR, Harrison MJ. Phosphate transport in Arabidopsis: Pht1;1 and Pht1;4 play a major role in phosphate acquisition from both low- and high-phosphate environments. Plant J. 2004;39:629-42.

47. Bariola PA, Howard CJ, Taylor CB, Verburg MT, Jaglan VD, Green PJ. The Arabidopsis ribonuclease gene RNS1 is tightly controlled in response to phosphate limitation. Plant J. 1994;6:673-85.

48. Yu B, Xu CC, Benning C. Arabidopsis disrupted in SQD2 encoding sulfolipid synthase is impaired in phosphate-limited growth. Proc Natl Acad Sci U S A. 2002;99:5732-7.

49. Cruz-Ramírez A, Oropeza-Aburto A, Razo-Hernández F, Ramírez-Chávez E, Herrera-Estrella L. Phospholipase DZ2 plays an important role in extraplastidic galactolipid biosynthesis and phosphate recycling in Arabidopsis roots. Proc Natl Acad Sci U S A. 2006;103:6765-70.

50. Sun $S B$, Gu M, Cao Y, Huang XP, Zhang X, Ai PH, Zhao JN, Fan XR, Xu $\mathrm{GH}$. A constitutive expressed phosphate transporter, OsPht1;1, modulates phosphate uptake and translocation in phosphate-replete rice. Plant Physiol. 2012;159:1571-81.

51. Wang XF, Wang YF, Piñeros MA, Wang Z, Wang W, Li C, Wu Z, Kochian LV, Wu P. Phosphate transporters OsPHT1;9 and OsPHT1;10 are involved in phosphate uptake in rice. Plant Cell Environ. 2014;37:1159-70.

52. Li YT, Zhang J, Zhang X, Fan HM, Gu M, Qu HY, Xu GH. Phosphate transporter OsPht 1;8 in rice plays an important role in phosphorus redistribution from source to sink organs and allocation between embryo and endosperm of seeds. Plant Sci. 2015;230:23-32. 
53. Zhang F, Sun YF, Pei WX, Jain A, Sun R, Cao Y, Wu XR, Jiang TT, Zhang L, Fan XR, et al. Involvement of OsPht1;4 in phosphate acquisition and mobilization facilitates embryo development in rice. Plant J. 2015;82:556-69.

54. Burleigh SH, Harrison MJ. The down-Regulation of Mt4-Like genes by phosphate fertilization occurs systemically and involves phosphate translocation to the shoots. Plant Physiol. 1999;119:241-8.

55. Thibaud MC, Arrighi JF, Bayle V, Chiarenza S, Creff A, Bustos R, Paz-Ares J, Poirier $Y$, Nussaume L. Dissection of local and systemic transcriptional responses to phosphate starvation in Arabidopsis. Plant J. 2010;64:775-89.

56. Jain A, Nagarajan VK, Raghothama KG. Transcriptional regulation of phosphate acquisition by higher plants. Cell Mol Life Sci. 2012;69:3207-24.

57. Sakuraba Y, Kim YS, Han SH, Lee BD, Paek NC. The Arabidopsis transcription Factor NAC016 promotes drought stress responses by repressing AREB1 transcription through a trifurcate feed-forward regulatory loop involving NAP. Plant Cell. 2015;27:1771-87.

58. Ross CA, Liu Y, Shen QJ. The WRKY gene family in rice (Oryza sativa). J Integr Plant Biol. 2007:49:827-42.

59. Dai XY, Wang YY, Zhang WH. OsWRKY74, a WRKY transcription factor, modulates tolerance to phosphate starvation in rice. J Exp Bot. 2015;67:947-60

60. Wang C, Ying S, Huang HJ, Li K, Wu P, Shou HX. Involvement of OsSPX1 in phosphate homeostasis in rice. Plant J. 2009;57:895-904.

61. Miura K, Hasegawa PM. Sumoylation and other ubiquitin-like posttranslational modifications in plants. Trends Cell Biol. 2010;20:223-32.

62. Park HC, Kim H, Koo SC, Park HJ, Cheong MS, Hong H, Baek D, Chung WS, Kim DH, Bressan RA, et al. Functional characterization of the SIZ/PIAS-type SUMO E3 ligases, OsSIZ1 and OsSIZ2 in rice. Plant Cell Environ. 2010;33:1923-34

63. Wang $H D$, Sun $R$, Cao $Y$, Pei WX, Sun YF, Zhou H, Wu XN, Zhang F, Luo L, Shen QR, et al. OsSIZ1, a SUMO E3 ligase gene, is involved in the regulation of the responses to phosphate and nitrogen in rice. Plant Cell Physiol. 2015;56:2381-95.

64. Chen JY, Liu Y, Ni J, Wang YF, Bai YH, Shi J, Gan J, Wu ZC, Wu P. OsPHF1 regulates the plasma membrane localization of low-and high-affinity inorganic phosphate transporters and determines inorganic phosphate uptake and translocation in rice. Plant Physiol. 2011;157:269-78.

65. Upadhyaya NM, Surin B, Ramm K, Gaudron J, Schunmann PHD, Taylor W, Waterhouse PM, Wang MB. Agrobacterium-mediated transformation of Australian rice cultivars Jarrah and Amaroo using modified promoters and selectable markers. Aust J Plant Physiol. 2000;27:201-10.

66. Jia HF, Ren HY, Gu M, Zhao JN, Sun SB, Zhang X, Chen JY, Wu P, Xu GH. The phosphate transporter gene OsPht1;8 is involved in phosphate homeostasis in rice. Plant Physiol. 2011;156:1164-75.

\section{Submit your next manuscript to BioMed Central and we will help you at every step:}

- We accept pre-submission inquiries

- Our selector tool helps you to find the most relevant journal

- We provide round the clock customer support

- Convenient online submission

- Thorough peer review

- Inclusion in PubMed and all major indexing services

- Maximum visibility for your research

Submit your manuscript at www.biomedcentral.com/submit

C) Biomed Central 